Supplementary Information for

\title{
Elucidating Monomer Character of an Alkenyl Boronate through Radical Copolymerization Leads to Copolymer Synthesis beyond the Limitation of Copolymerizability by Side-Chain Replacement
}

\author{
Hiroshi Makino, Tsuyoshi Nishikawa* and Makoto Ouchi*
}

Department of Polymer Chemistry, Graduate School of Engineering, Kyoto University, Kyoto 606-8501, Japan

615-8510, Japan

*To whom correspondence should be addressed.

E-mail: nishikawa.tsuyoshi.8n@kyoto-u.ac.jp

ouchi@living.polym.kyoto-u.ac.jp

\section{Contents}

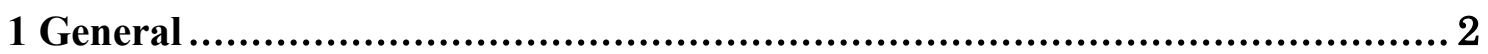

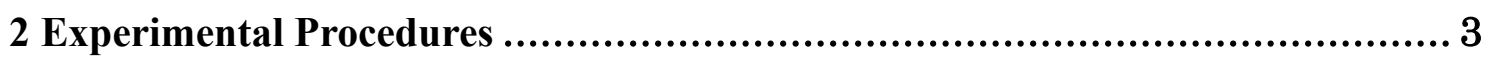

3 Solubility Test of Obtained Polymers ................................................. 28

4 Thermal Property of Obtained Polymers.......................................... 29

5 Controlled Radical Copolymerization of IPBpin with St ......................... 31

6 Computational Study for Radical Copolymerization Behavior ..................... 32

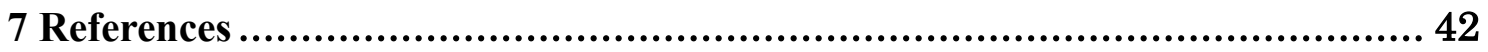




\section{General}

All reactions were carried out with magnetic stirring under a nitrogen or an argon atmosphere unless stated otherwise. ${ }^{1} \mathrm{H}$ NMR spectra were recorded on a JEOL JNM-ECA500 operating at $500.16 \mathrm{MHz}\left({ }^{1} \mathrm{H}\right)$ at ambient temperature. ${ }^{1} \mathrm{H}$ NMR data are reported on the basis of the chemical shift in ppm downfield from tetramethylsilane $(\delta$ scale). IR spectra were obtained using an Agilent Technologies Cary 630 FTIR spectrometer. The number-average molecular weight $\left(M_{\mathrm{n}}\right)$ and $M_{\mathrm{w}} / M_{\mathrm{n}}$ ratio of polymers were measured by size exclusion chromatography (SEC) at $40{ }^{\circ} \mathrm{C}$ in THF as an eluent on two polystyrene-gel columns (TOSOH TSKgel Super Multipore HZ-M). The columns were calibrated against standard polystyrene samples (TOSOH PStQuick series). Preparative SEC was performed using JAIGEL-2.5HR or Shodex KF-5001 columns $\left(\mathrm{CHCl}_{3}\right)$. For dialysis, MWCO1000 (Spectra/PorVR7, diameter $11.5 \mathrm{~mm}$ ) was used. Differential scanning calorimetry (DSC) was performed for polymer samples (ca. 3-5 $\mathrm{mg}$ in aluminum pan) under dry nitrogen flow on DSCQ200 calorimeter (TA Instruments) equipped with RCS 90 electric freezing machine. The heating and cooling rates were performed at $10{ }^{\circ} \mathrm{C} / \mathrm{min}$ and $-10{ }^{\circ} \mathrm{C} / \mathrm{min}$, respectively, between $-80{ }^{\circ} \mathrm{C}$ and $200{ }^{\circ} \mathrm{C}$. The second heating scans were employed as data in the work. Thermogravimetric analysis (TGA) of polymer samples (ca. 3-5 mg in aluminum pan) was performed under dry nitrogen flow on a STA 2500 Regulus (NETZSCH). The heating rate was at $10{ }^{\circ} \mathrm{C} / \mathrm{min}$, between $20{ }^{\circ} \mathrm{C}$ and $500{ }^{\circ} \mathrm{C}$.

2-propenylboronic acid pinacol ester (IPBpin), Methyl methacrylate (MMA), Methyl acrylate (MA), Styrene (St), 2-Propenyl acetate (IPOAc), Vinyl acetate (VOAc), Acrylonitrile (AN), Isobutyl vinyl ether (IBVE) and tetralin were purified by distillation prior to use. Azobisisobutyronitrile (AIBN), 2-Cyano-2-propyl dodecyl trithiocarbonate (CPDT), aqueous hydrogen peroxide (30wt\%), sodium hydroxide, dehydrated toluene and ethanol were purchased from the commercial sources and were used without further purification. 


\section{Experimental Procedures}

\section{General method of free radical copolymerization of IPBpin with common vinyl monomers:}

The following shows a copolymerization method using St as a comonomer. A toluene solution of AIBN ( $4.9 \mathrm{mg}, 30 \mu \mathrm{mol})$ was placed in a Schlenk tube under Ar atmosphere. Tetralin $(40.9 \mu \mathrm{L}, 39.7 \mathrm{mg}, 300 \mu \mathrm{mol}$, internal standard), IPBpin $(282 \mu \mathrm{L}, 252 \mathrm{mg}, 1.50$ mmol), St (172 $\mu \mathrm{L}, 156 \mathrm{mg}, 1.5 \mathrm{mmol})$ and toluene $(513 \mu \mathrm{L})$ were added at room temperature. The reaction mixture was stirred at $60{ }^{\circ} \mathrm{C}$ in an oil bath. After $96 \mathrm{~h}$, the polymerization was stopped by cooling in the use of freezer (At this time, $M_{\mathrm{n}}=9.8 \times 10^{3}$, $M_{\mathrm{w}} / M_{\mathrm{n}}=1.87$, it was judged by SEC calibrated by polystyrene standard in the use of THF as an eluent). Concentration by evaporation was followed by purification using preparative SEC, affording a poly(2-propenyl boronic acid pinacol ester-co-styrene) (P(IPBpin-co-St), $139 \mathrm{mg}$ ) as colorless solid.

EMI, MMA, MA, VOAc, AN and IBVE were copolymerized with IPBpin according to general method.

All asterisks in the following ${ }^{1} \mathrm{H}$ NMR spectra highlight residual $\mathrm{H}_{2} \mathrm{O}$ peak.

Scheme S1. Radical copolymerization of IPBpin with St

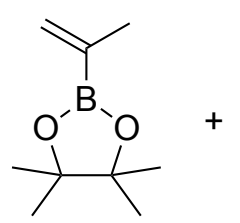

IPBpin (1.0 M)<smiles>C=Cc1ccccc1</smiles>

St $(1.0 \mathrm{M})$ $\underset{\text { Toluene, } 60{ }^{\circ} \mathrm{C}}{\stackrel{\text { AIBN }(20 \mathrm{mM})}{\longrightarrow}}$<smiles>CC(C)(C)CC(C)(B1OC(C)(C)C(C)(C)O1)C(C)(C)C</smiles> 
(a)

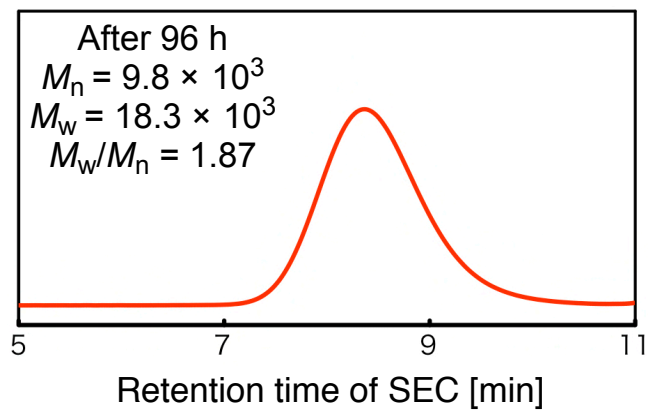

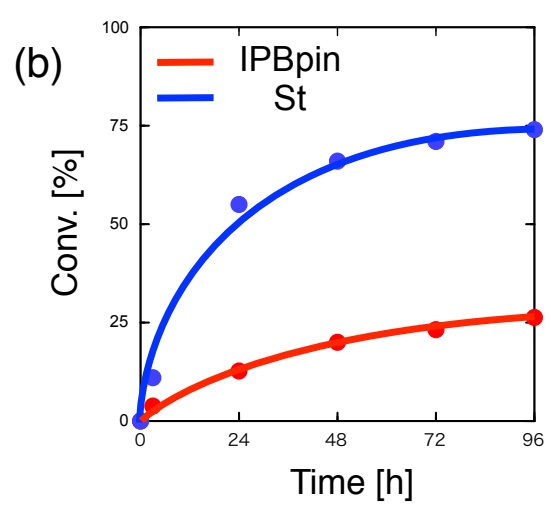

Figure S1. (a) SEC trace of the reaction mixture after 96 h. (b) Time-conversion curves of radical copolymerization of IPBpin with St.

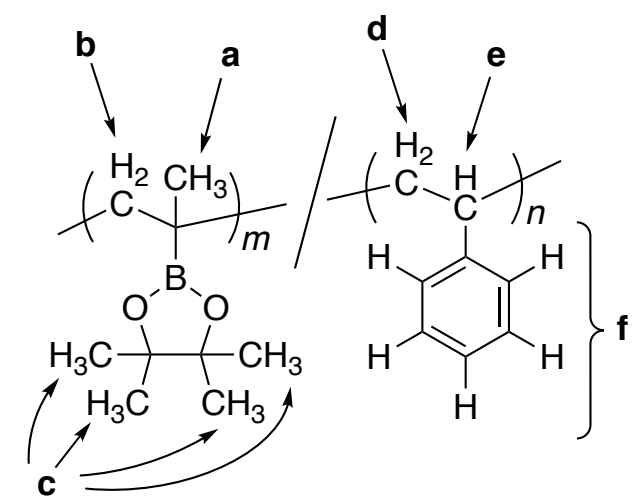

Figure S2. The molecular structure of $\mathrm{P}(\mathrm{IPBpin}-\mathrm{co}-\mathrm{St})$ with its ${ }^{1} \mathrm{H}$ NMR assignment. 


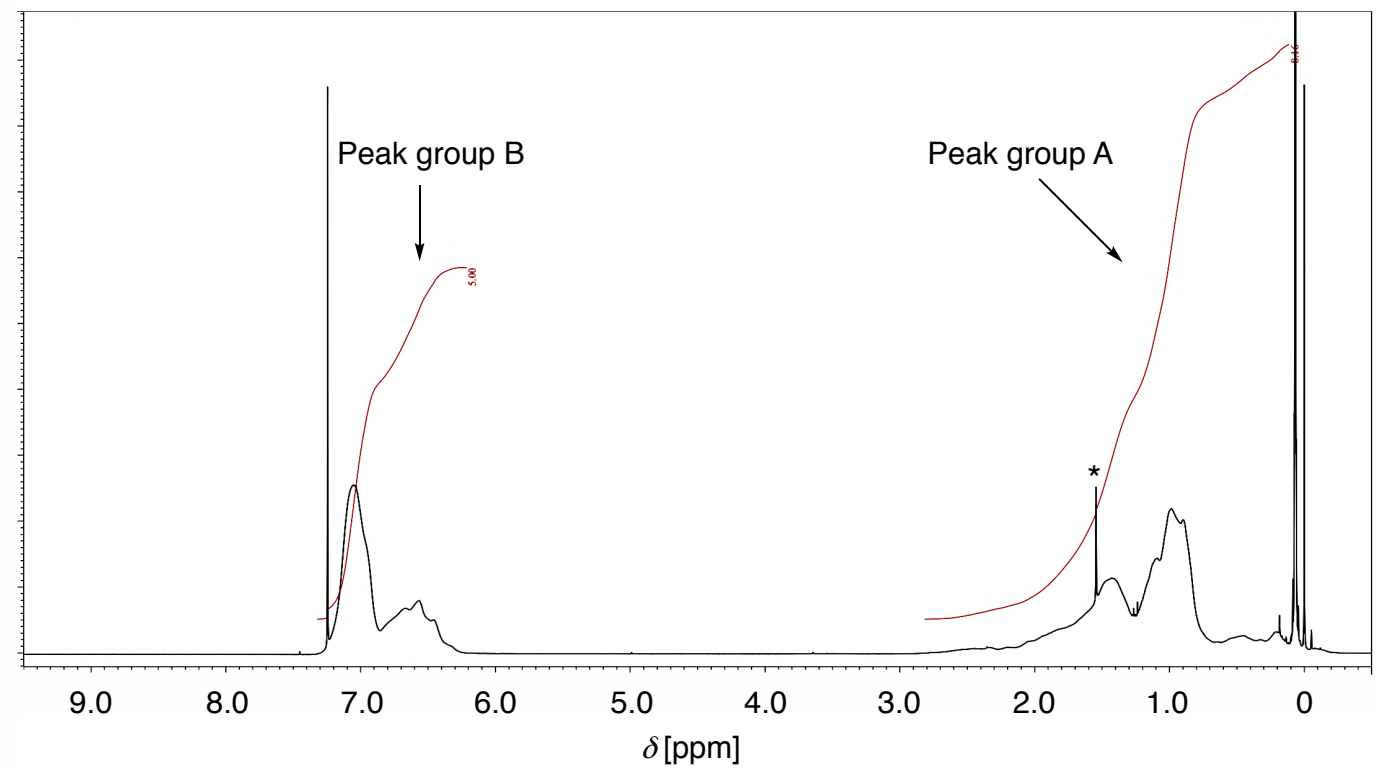

Figure S3. ${ }^{1} \mathrm{H}$ NMR spectrum of $\mathrm{P}(\mathrm{IPBpin}-\mathrm{co}-\mathrm{St})$ in $\mathrm{CDCl}_{3}$.

The peak group A is corresponding to protons a-e. And, the peak group B is corresponding to protons $\mathbf{f}$. Therefore, copolymerization ratio $(m: n)$ can be estimated as follows:

$$
\begin{gathered}
8.16: 5.00=17 m+3 n: 5 n \\
m: n=23: 77
\end{gathered}
$$

These values are basically consistent with conversion-based copolymerization ratio $(\mathrm{IPBpin}=26.2 \%, \mathrm{St}=73.8 \%)$. 
Scheme S2. Radical copolymerization of IPBpin with MMA
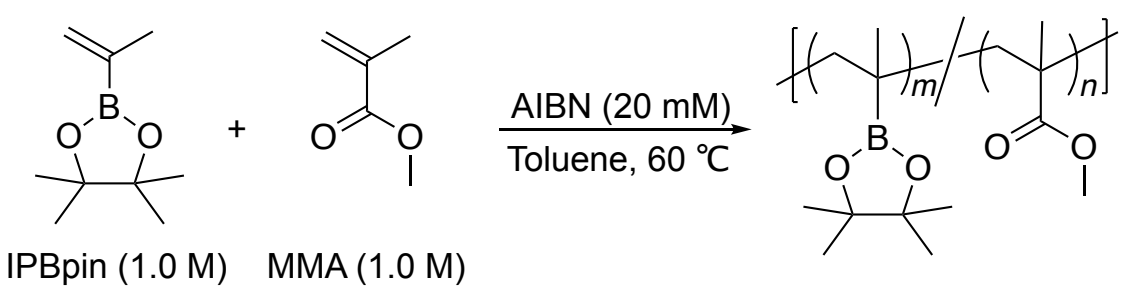

(a)

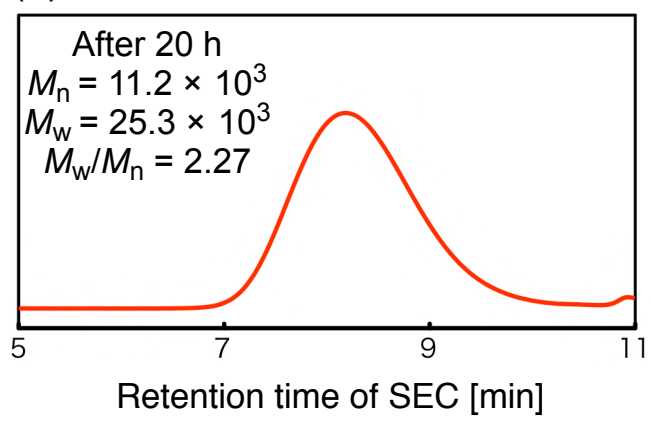

(b)

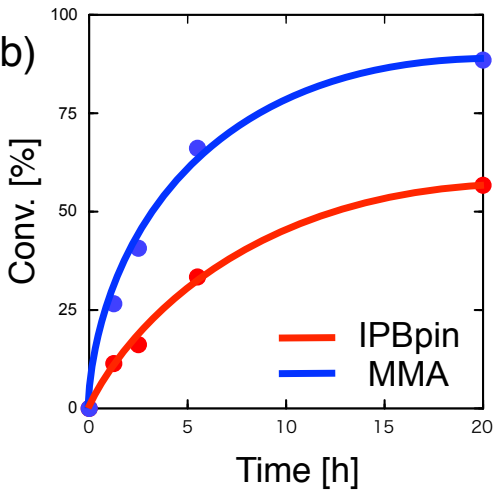

Figure S4. (a) SEC trace of the reaction mixture after $20 \mathrm{~h}$. (b) Time-conversion curves of radical copolymerization of IPBpin with MMA.

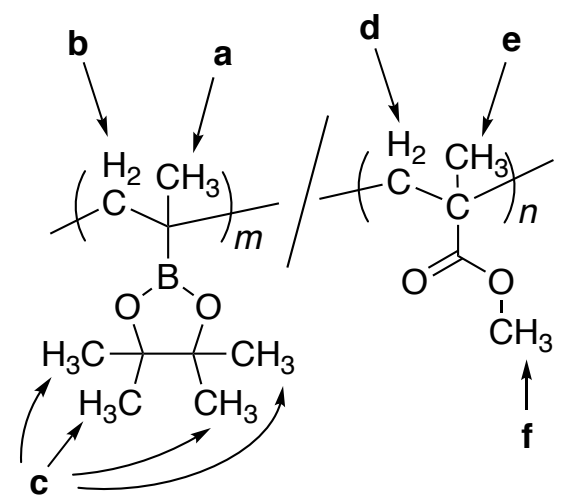

Figure S5. The molecular structure of $\mathrm{P}(\mathrm{IPBpin}-c o-\mathrm{MMA})$ with its ${ }^{1} \mathrm{H}$ NMR assignment. 


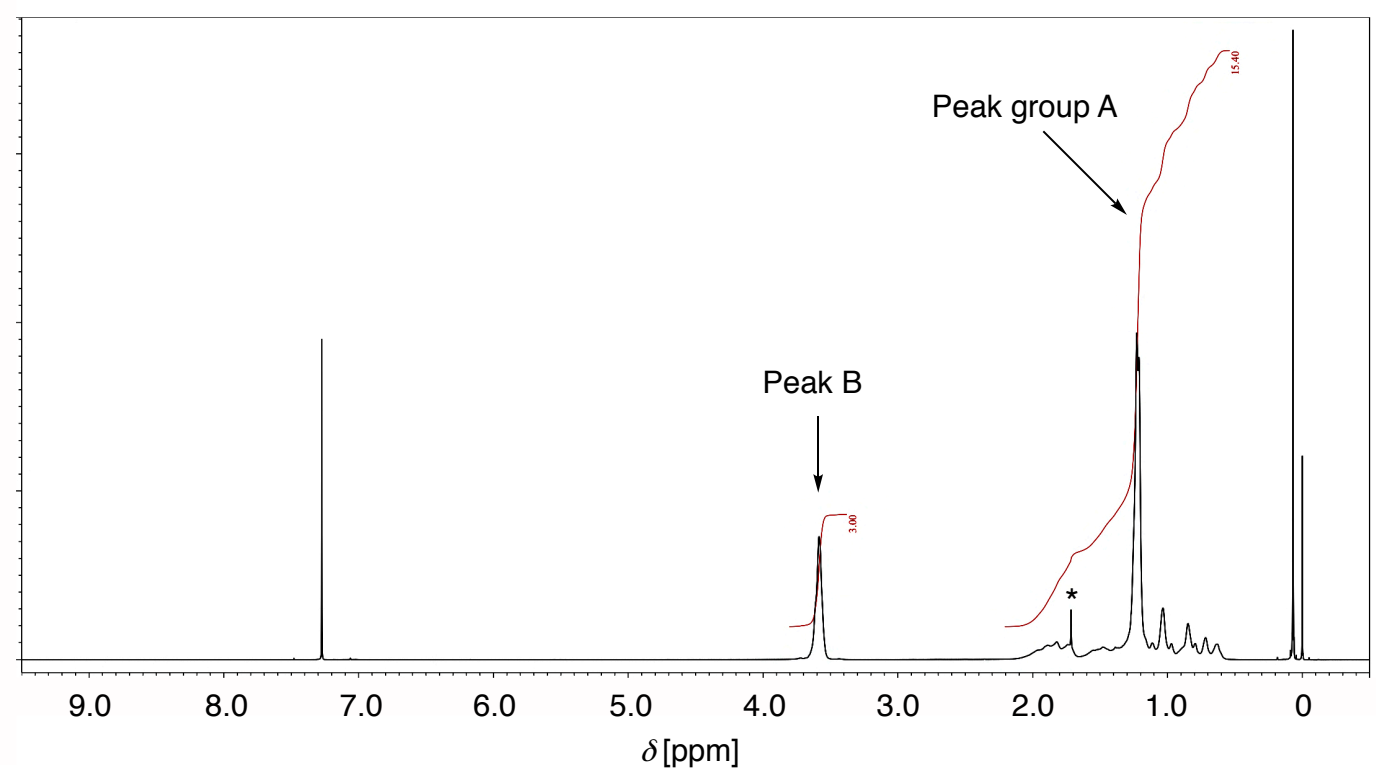

Figure S6. ${ }^{1} \mathrm{H}$ NMR spectrum of $\mathrm{P}(\mathrm{IPBpin}-\mathrm{co}-\mathrm{MMA})$ in $\mathrm{CDCl}_{3}$.

The peak group A is corresponding to protons a-e. And, the peak group B is corresponding to protons $\mathbf{f}$. Therefore, copolymerization ratio $(m: n)$ can be estimated as follows:

$$
\begin{aligned}
15.40: 3.00 & =17 m+5 n: 3 n \\
m: n & =38: 62
\end{aligned}
$$

These values are basically consistent with conversion-based copolymerization ratio $(\mathrm{IPBpin}=39.0 \%, \mathrm{MMA}=61.0 \%)$. 
Scheme S3. Radical copolymerization of IPBpin with MA
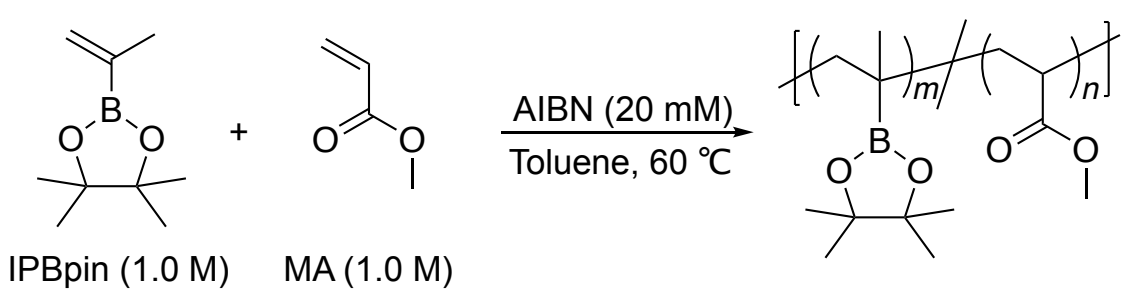

(a)

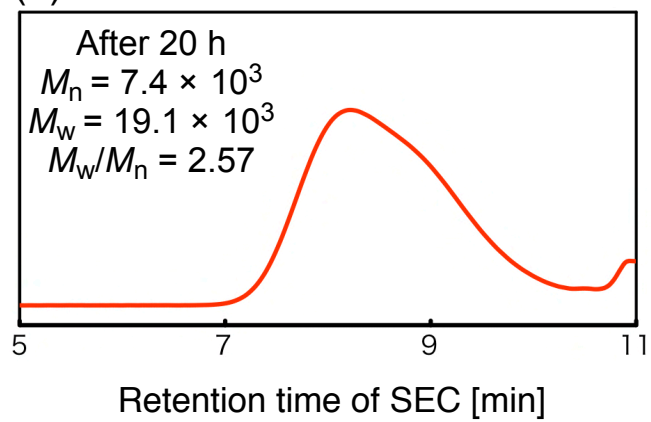

(b)

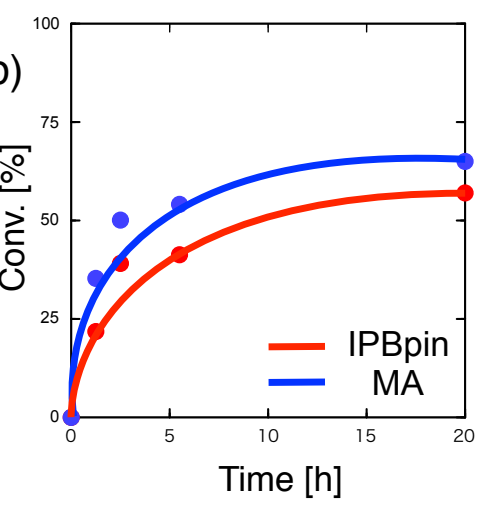

Figure S7. (a) SEC trace of the reaction mixture after 20 h. (b) Time-conversion curves of radical copolymerization of IPBpin with MA.

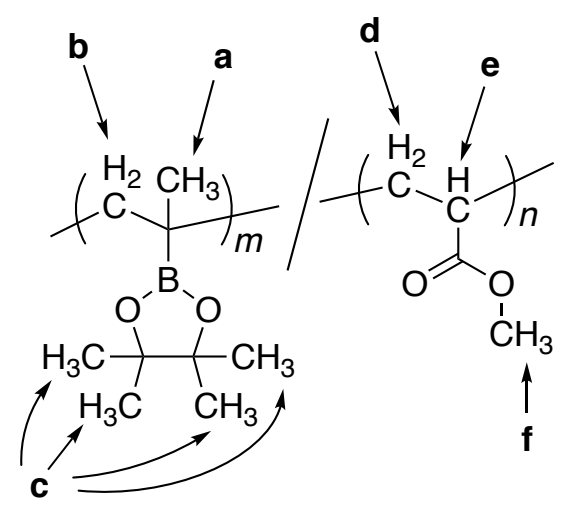

Figure S8. The molecular structure of $\mathrm{P}(\mathrm{IPBpin}-\mathrm{co}-\mathrm{MA})$ with its ${ }^{1} \mathrm{H}$ NMR assignment. 


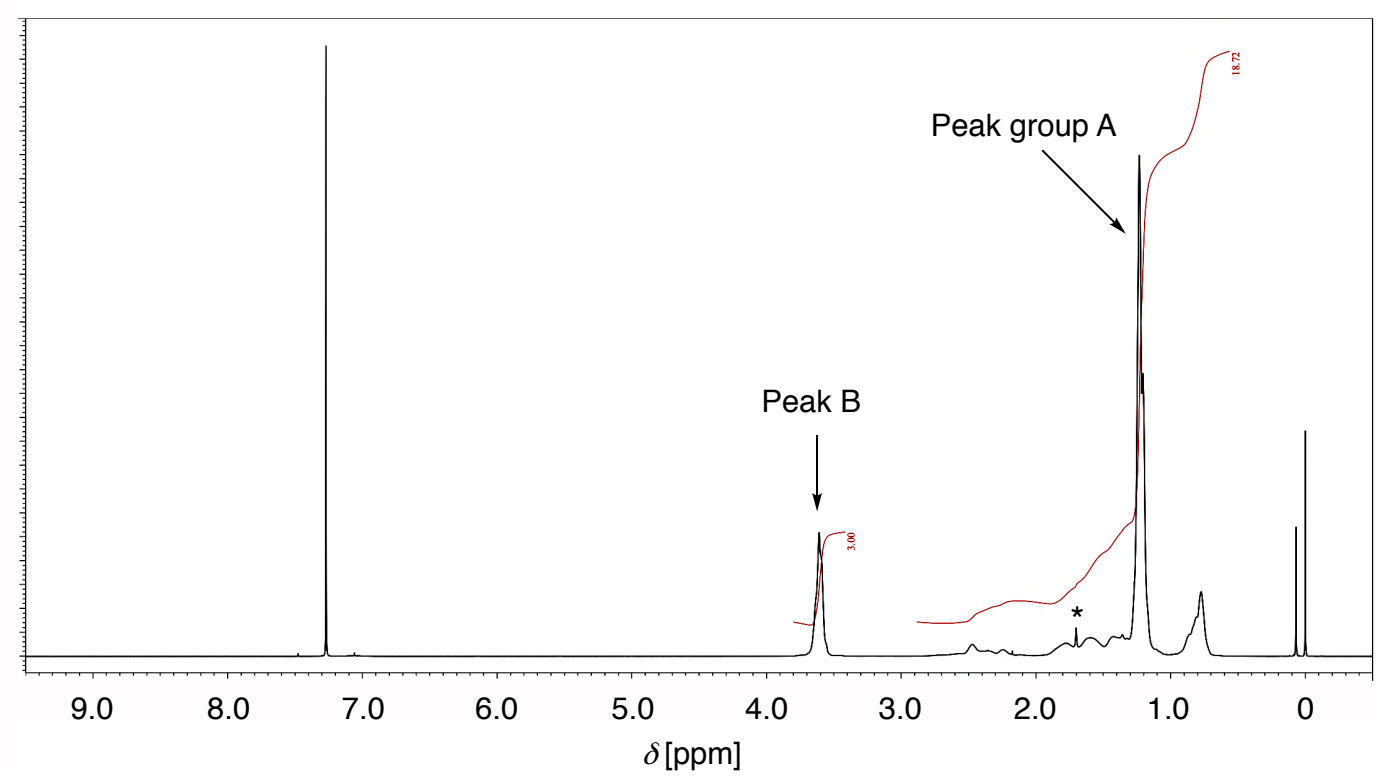

Figure S9. ${ }^{1} \mathrm{H}$ NMR spectrum of $\mathrm{P}(\mathrm{IPBpin}-\mathrm{co}-\mathrm{MA})$ in $\mathrm{CDCl}_{3}$.

The peak group A is corresponding to protons a-e. And, the peak group B is corresponding to protons $\mathbf{f}$. Therefore, copolymerization ratio $(m: n)$ can be estimated as follows:

$$
\begin{aligned}
18.72: 3.00 & =17 m+3 n: 3 n \\
m: n & =48: 52
\end{aligned}
$$

These values are basically consistent with conversion-based copolymerization ratio $(\mathrm{IPBpin}=46.7 \%, \mathrm{MA}=53.3 \%)$. 
Scheme S4. Radical copolymerization of IPBpin with AN

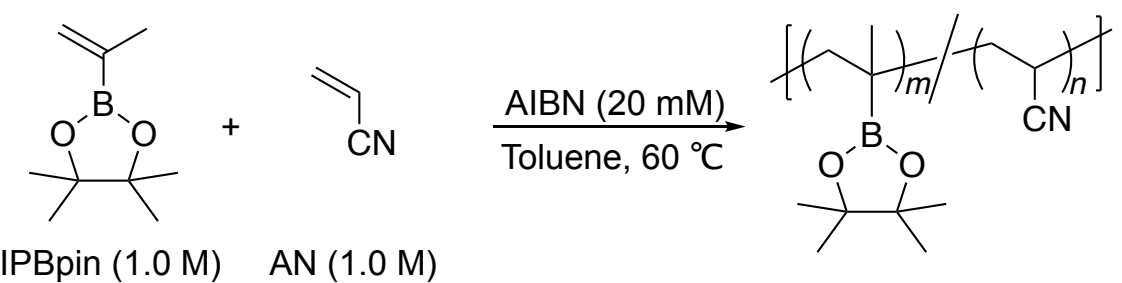

(a)

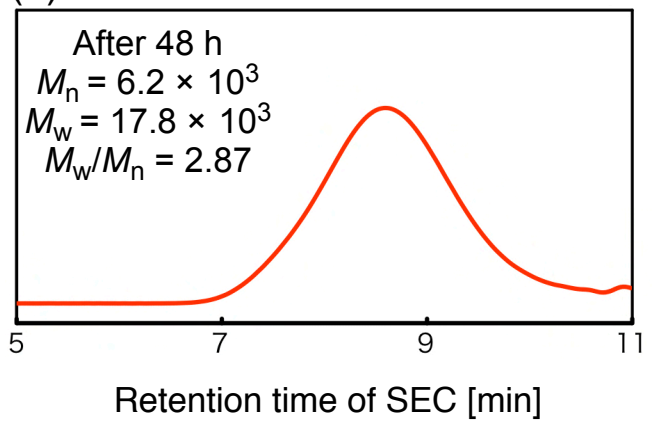

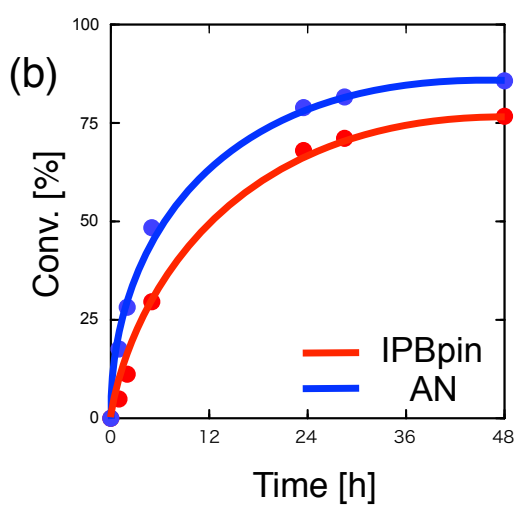

Figure S10. (a) SEC trace of the reaction mixture after $48 \mathrm{~h}$. (b) Time-conversion curves of radical copolymerization of IPBpin with AN.

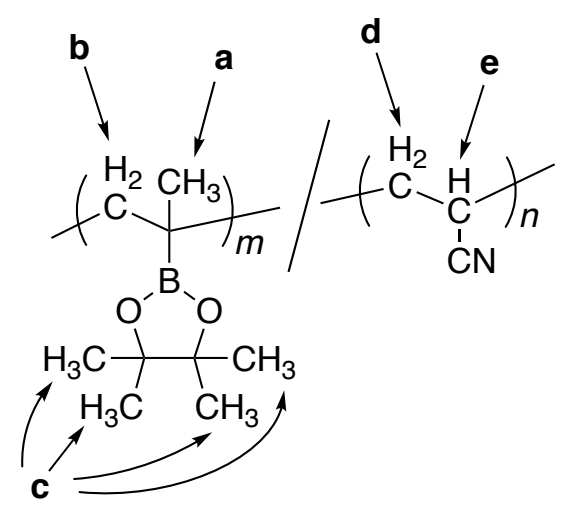

Figure S11. The molecular structure of $\mathrm{P}(\mathrm{IPBpin}-\mathrm{co}-\mathrm{AN})$ with its ${ }^{1} \mathrm{H}$ NMR assignment. 


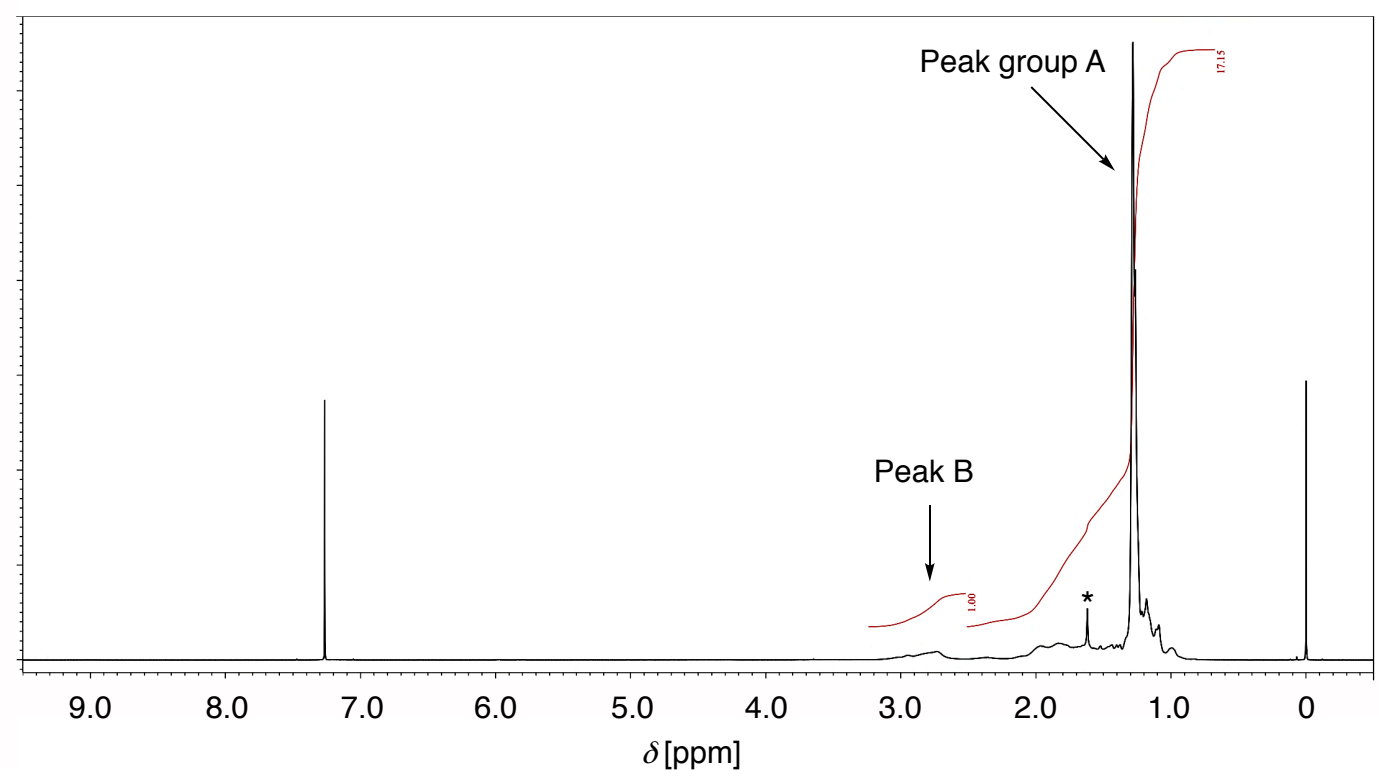

Figure S12. ${ }^{1} \mathrm{H}$ NMR spectrum of $\mathrm{P}(\mathrm{IPBpin}-\mathrm{co}-\mathrm{AN})$ in $\mathrm{CDCl}_{3}$.

The peak group A is corresponding to protons a-d. And, the peak B is corresponding to protons e. Therefore, copolymerization ratio $(m: n)$ can be estimated as follows:

$$
\begin{gathered}
17.15: 1.00=17 m+2 n: n \\
m: n=47: 53
\end{gathered}
$$

These values are basically consistent with conversion-based copolymerization ratio $(\mathrm{IPBpin}=47.4 \%, \mathrm{AN}=52.6 \%)$. 
Scheme S5. Radical copolymerization of IPBpin with EMI

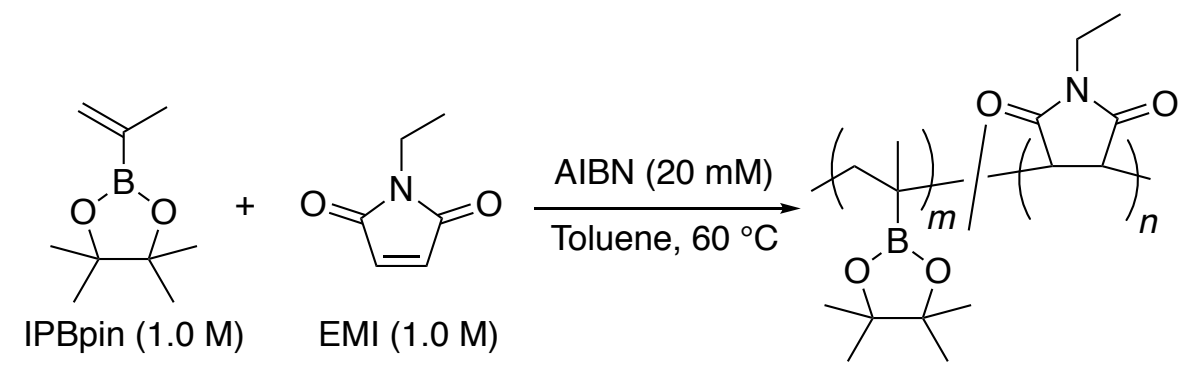

(a)

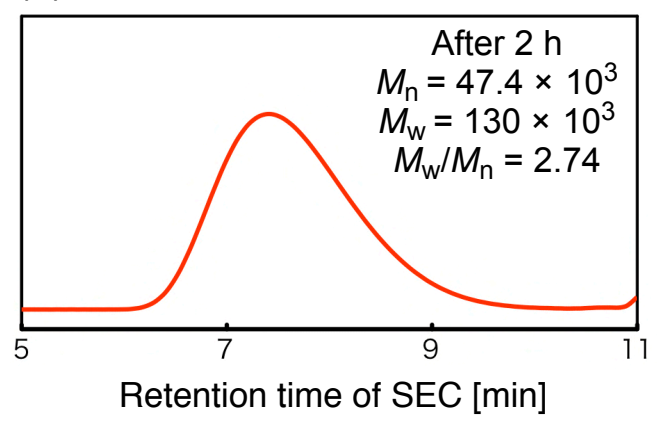

(b)

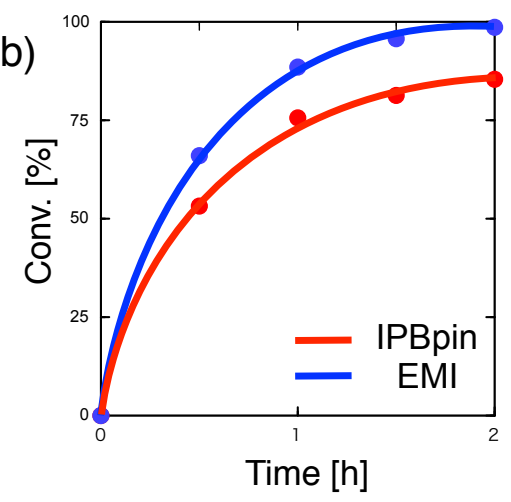

Figure S13. (a) SEC trace of the reaction mixture after 2 h. (b) Time-conversion curves of radical copolymerization of IPBpin with EMI.

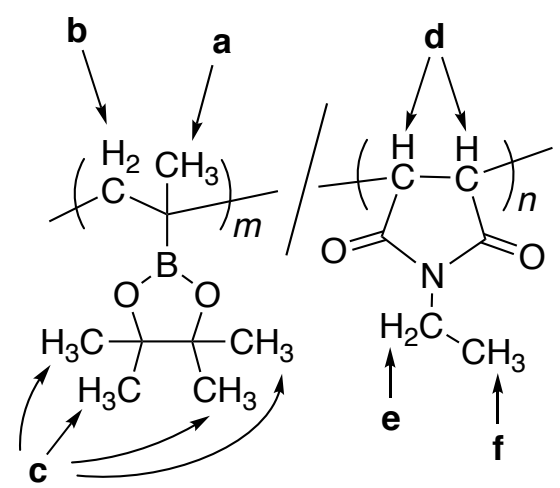

Figure S14. The molecular structure of $\mathrm{P}(\mathrm{IPBpin}-\mathrm{co}-\mathrm{EMI})$ with its ${ }^{1} \mathrm{H}$ NMR assignment. 


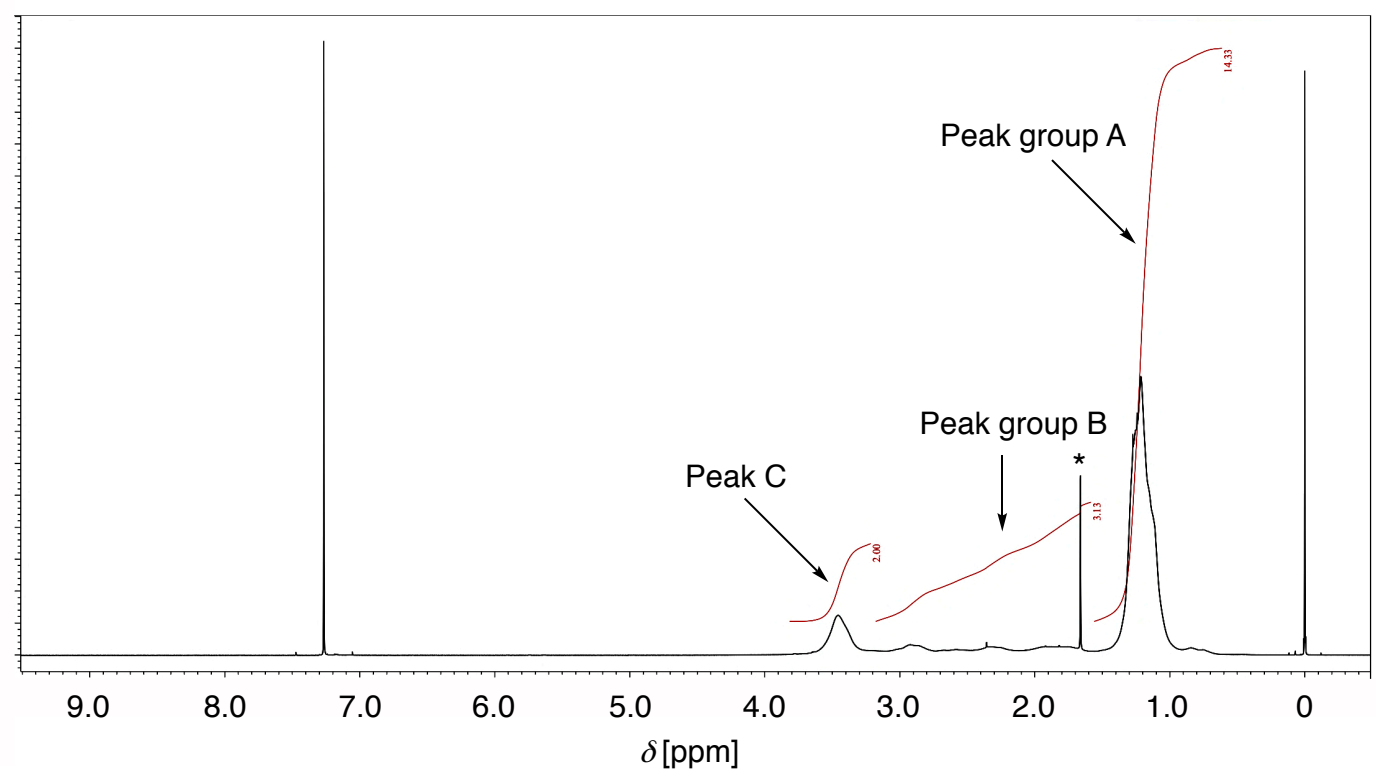

Figure S15. ${ }^{1} \mathrm{H}$ NMR spectrum of $\mathrm{P}(\mathrm{IPBpin}-\mathrm{co}-\mathrm{EMI})$ in $\mathrm{CDCl}_{3}$.

The peak group A is corresponding to protons a,c,f. And, the peak group B is corresponding to protons b,d. Finally, the peak $\mathrm{C}$ is corresponding to protons e. Therefore, copolymerization ratio $(m: n)$ can be estimated as follows:

$$
\begin{aligned}
14.33: 2.00 & =15 m+3 n: 2 n \\
m: n & =43: 57
\end{aligned}
$$

These values are basically consistent with conversion-based copolymerization ratio $(\mathrm{IPBpin}=46.4 \%, \mathrm{EMI}=53.6 \%)$. 
Scheme S6. Radical copolymerization of IPBpin with IBVE
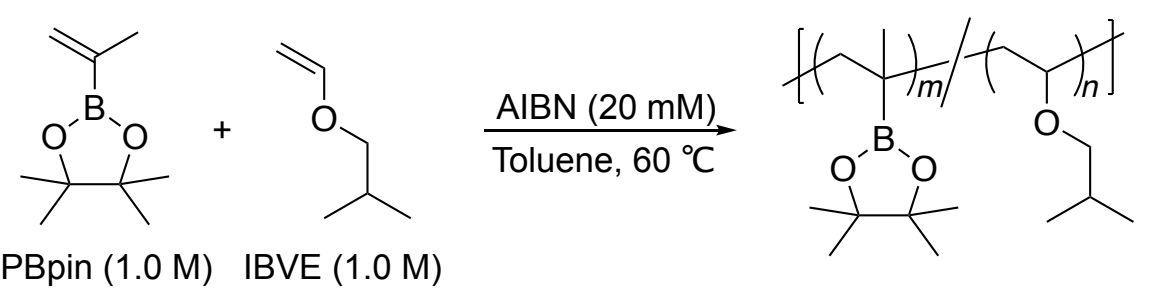

(a)

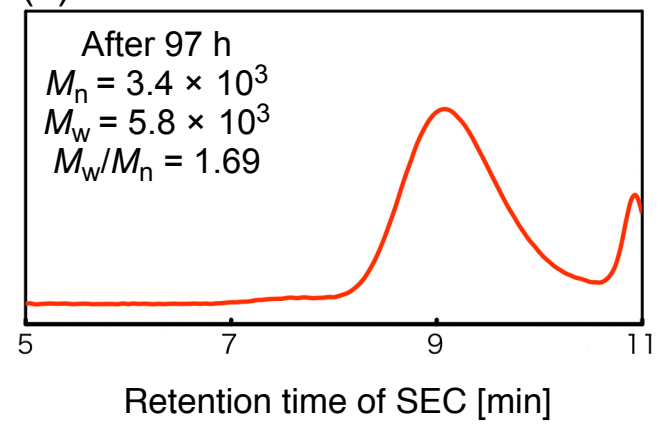

(b)

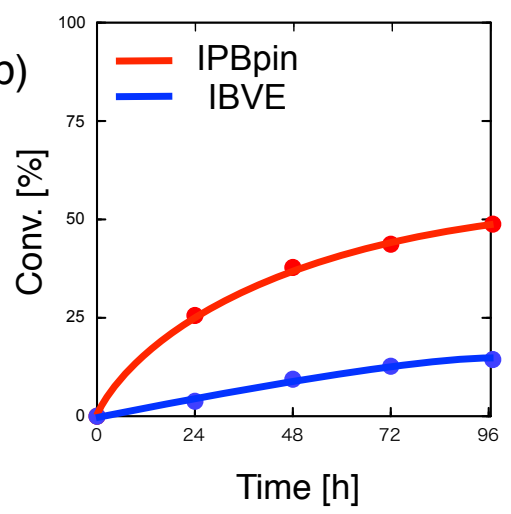

Figure S16. (a) SEC trace of the reaction mixture after 97 h. (b) Time-conversion curves of radical copolymerization of IPBpin with IBVE.

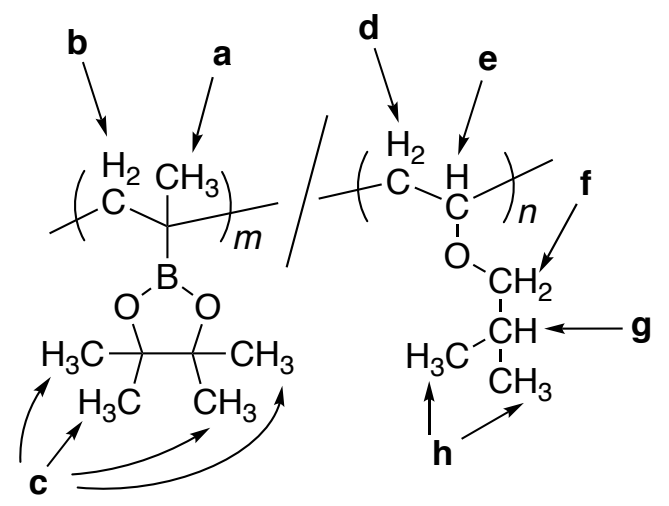

Figure S17. The molecular structure of $\mathrm{P}\left(\mathrm{IPBpin}-\mathrm{co}\right.$-IBVE) with its ${ }^{1} \mathrm{H}$ NMR assignment. 


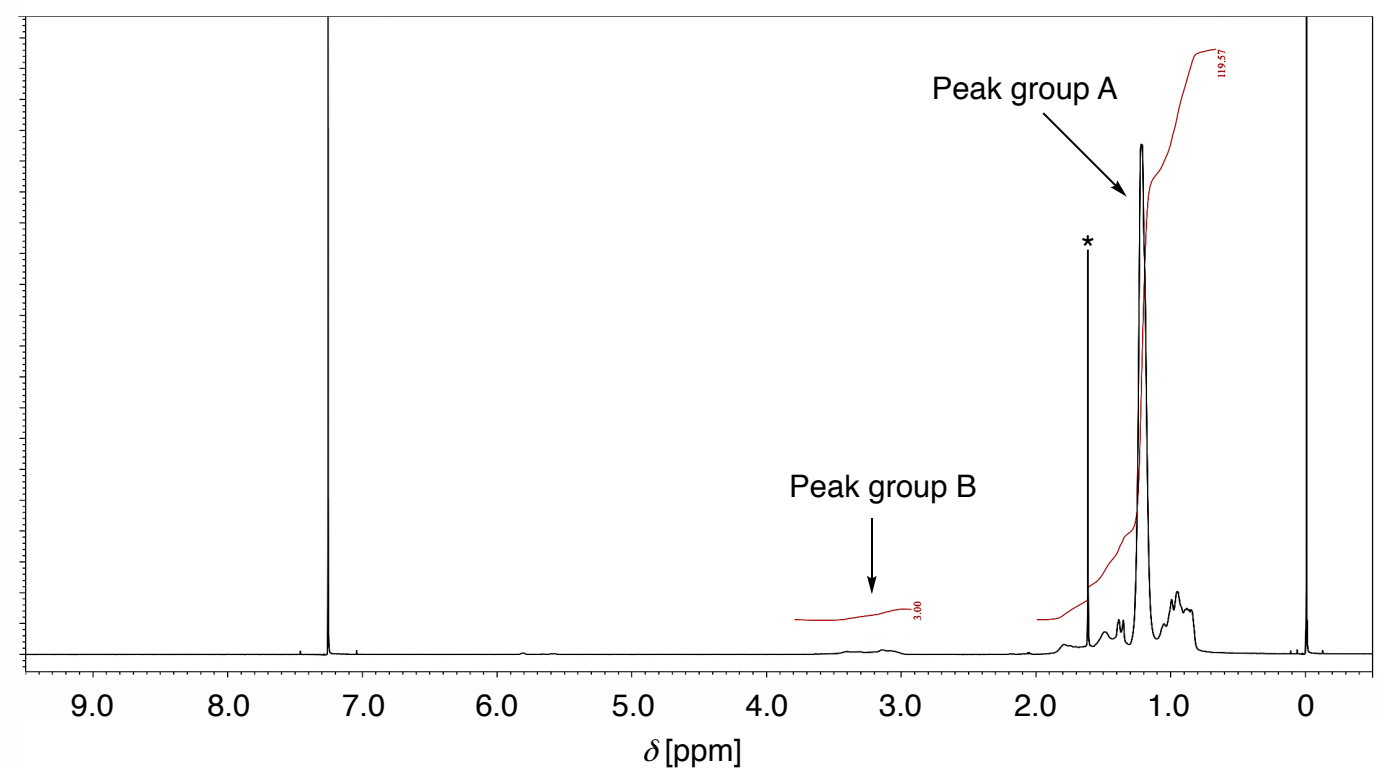

Figure S18. ${ }^{1} \mathrm{H}$ NMR spectrum of $\mathrm{P}(\mathrm{IPBpin}-\mathrm{co}-\mathrm{IBVE})$ in $\mathrm{CDCl}_{3}$.

The peak group A is corresponding to protons a-d,g,h. And, the peak group B is corresponding to protons e,f. Therefore, copolymerization ratio $(m: n)$ can be estimated as follows:

$$
\begin{gathered}
119.57: 3.00=17 m+9 n: 3 n \\
m: n=87: 13
\end{gathered}
$$

The slight difference of this result from conversion-based copolymerization ratio $(\mathrm{IPBpin}=77.2 \%, \mathrm{IBVE}=22.8 \%)$ may be ascribed to the purification by preparative SEC resulting in removal of low-molecular weight oligomers, which was formed because of the combination of conjugated- and unconjugated-type monomers.

\section{Free radical polymerization of $\mathrm{St}$}

For measurement of physical properties (Figure 5 in main text), St homopolymer was prepared as follows: AIBN (34.48 $\mathrm{mg}, 0.21 \mathrm{mmol})$ was placed in a Schlenk tube under air. After the tube was carried in a globe box chamber, tetralin $(286 \mu \mathrm{L}, 277.63 \mathrm{mg}, 2.1$ mmol, internal srtandard), St $(2.40 \mathrm{~mL}, 2.19 \mathrm{~g}, 21 \mathrm{mmol})$ and toluene $(7.81 \mathrm{~mL})$ were added at room temperature. The reaction mixture was stirred at $60{ }^{\circ} \mathrm{C}$ in an oil bath. 
After $72 \mathrm{~h}$, the polymerization was stopped by cooling in the use of freezer (At this time, $M_{\mathrm{n}}=11.2 \times 10^{3}, M_{\mathrm{w}} / M_{\mathrm{n}}=1.76$, it was judged by SEC calibrated by polystyrene standard in the use of THF as an eluent). Concentration by evaporation was followed by purification using preparative SEC, affording polystyrene (PSt, $1.56 \mathrm{~g}$ ) as colorless solid.

Scheme S7. Radical polymerization of St

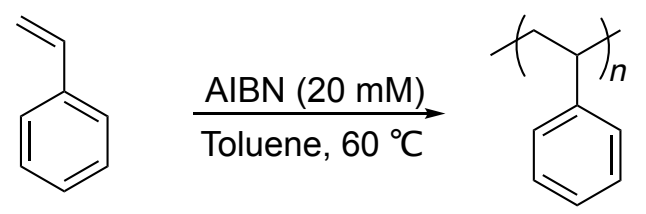

St $(2.0 \mathrm{M})$

(a)

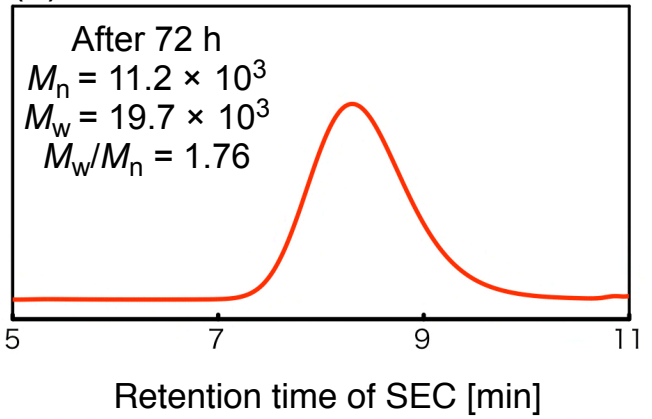

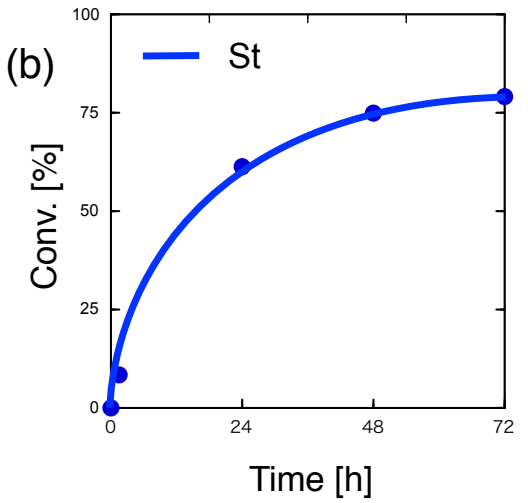

Figure S19. SEC trace of the reaction mixture after $72 \mathrm{~h}$. (b) Time-conversion curve of radical polymerization of St.

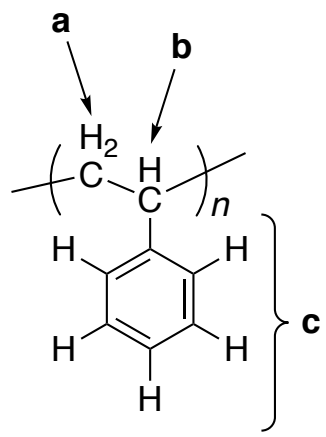

Figure S20. The molecular structure of PSt with its ${ }^{1} \mathrm{H}$ NMR assignment. 


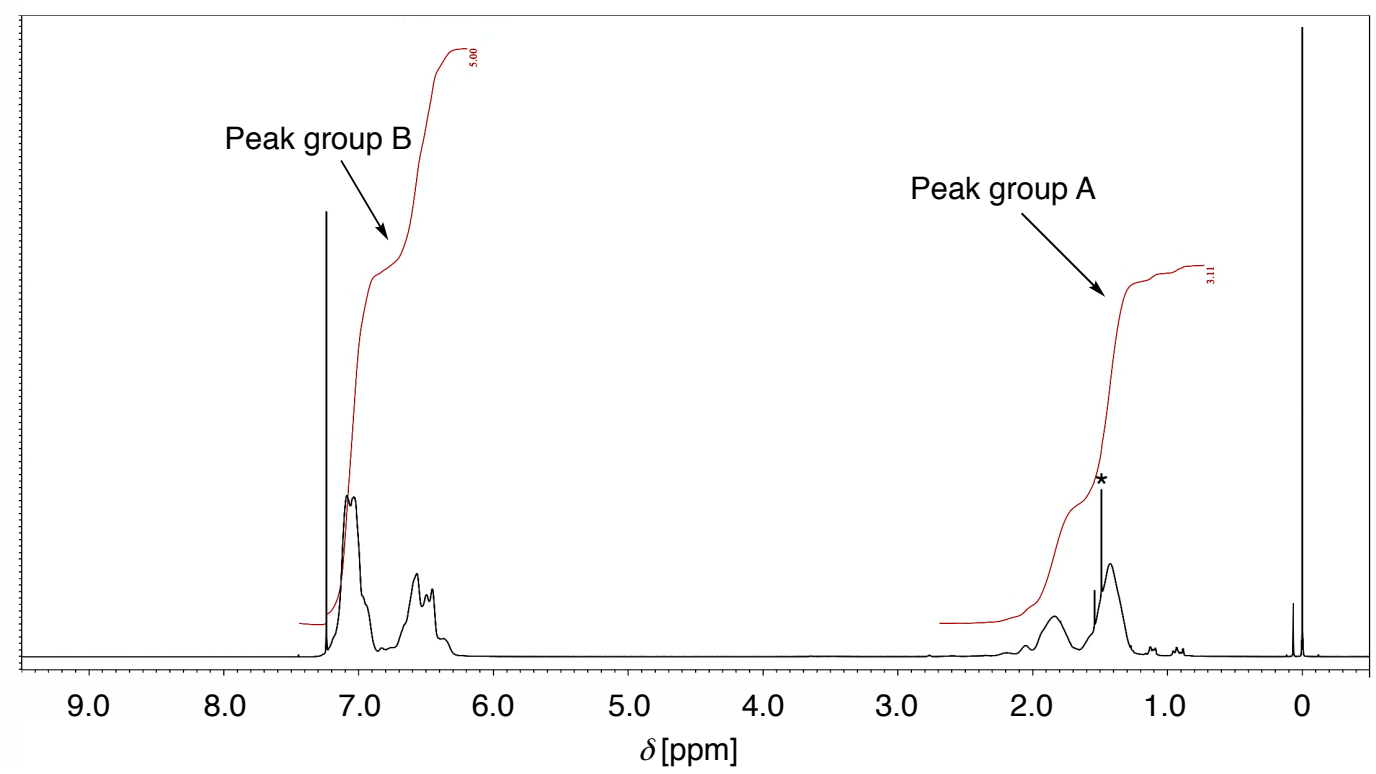

Figure S21. ${ }^{1} \mathrm{H}$ NMR spectrum of PSt in $\mathrm{CDCl}_{3}$.

The peak group A is corresponding to protons a,b. And, the peak group B is corresponding to protons c.

\section{Free radical copolymerization of St with IPOAc}

AIBN (34.48 mg, $0.21 \mathrm{mmol}$ ) was placed in a Schlenk tube under air. After the tube was carried in a globe box chamber, tetralin $(286 \mu \mathrm{L}, 277.63 \mathrm{mg}, 2.1 \mathrm{mmol}$, internal srtandard), St (1.20 mL, $1.09 \mathrm{~g}, 10.5 \mathrm{mmol}$ ), isopropenyl acetate (IPOAc; $1.14 \mathrm{~mL}, 1.05$ g, $10.5 \mathrm{mmol})$ and toluene $(7.87 \mathrm{~mL})$ were added at room temperature. The reaction mixture was stirred at $60{ }^{\circ} \mathrm{C}$ in an oil bath. After $72 \mathrm{~h}$, the polymerization was stopped by cooling in the use of freezer (At this time, $M_{\mathrm{n}}=5.8 \times 10^{3}, M_{\mathrm{w}} / M_{\mathrm{n}}=1.66$, it was judged by SEC calibrated by polystyrene standard in the use of THF as an eluent). Concentration by evaporation was followed by purification using preparative SEC, affording poly(styrene-co-isopropenyl acetate) (P(St-co-IPOAc)) as colorless solid. 
Scheme S8. Radical copolymerization of St with IPOAc

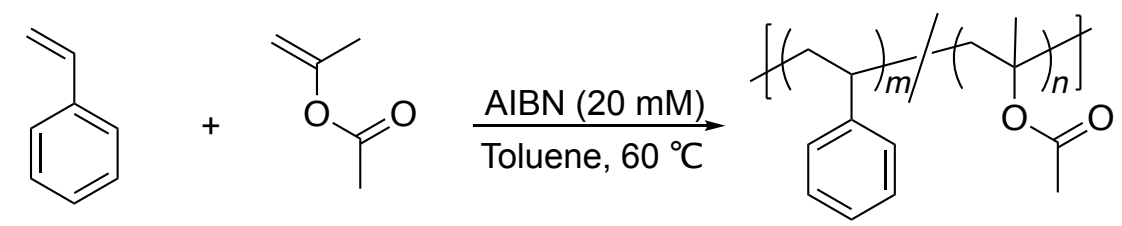

St $(1.0 \mathrm{M}) \quad$ IPOAc $(1.0 \mathrm{M})$

(a)

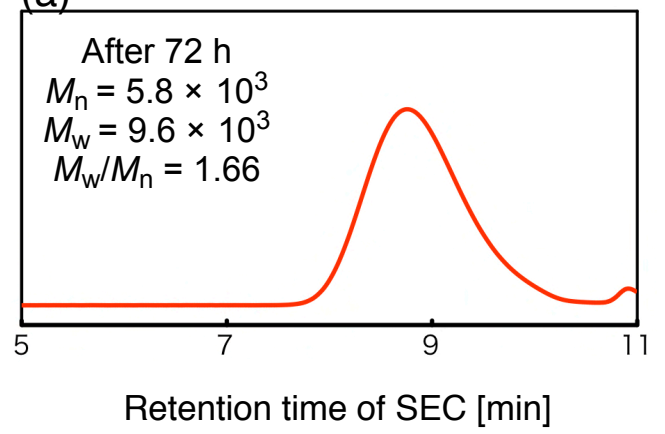

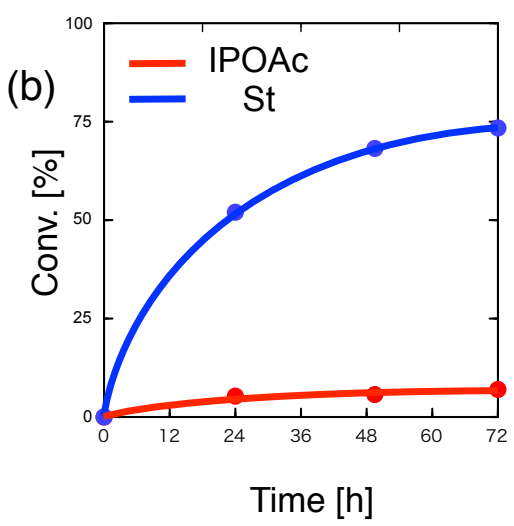

Figure S22. (a) SEC trace of the reaction mixture after $72 \mathrm{~h}$. (b) Time-conversion curve of radical copolymerization of St with IPOAc.

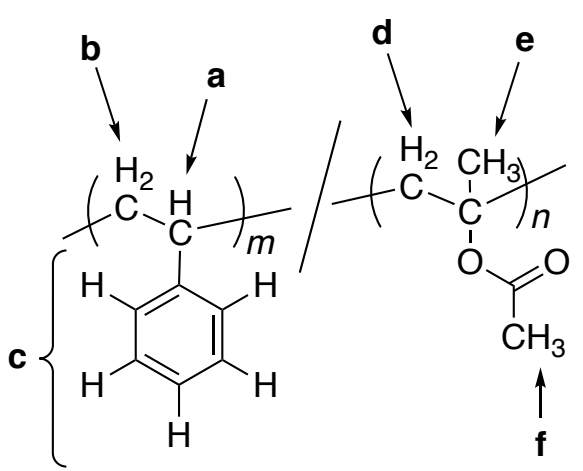

Figure S23. The molecular structure of $\mathrm{P}\left(\mathrm{St}-\mathrm{co}\right.$-IPOAc) with its ${ }^{1} \mathrm{H}$ NMR assignment. 


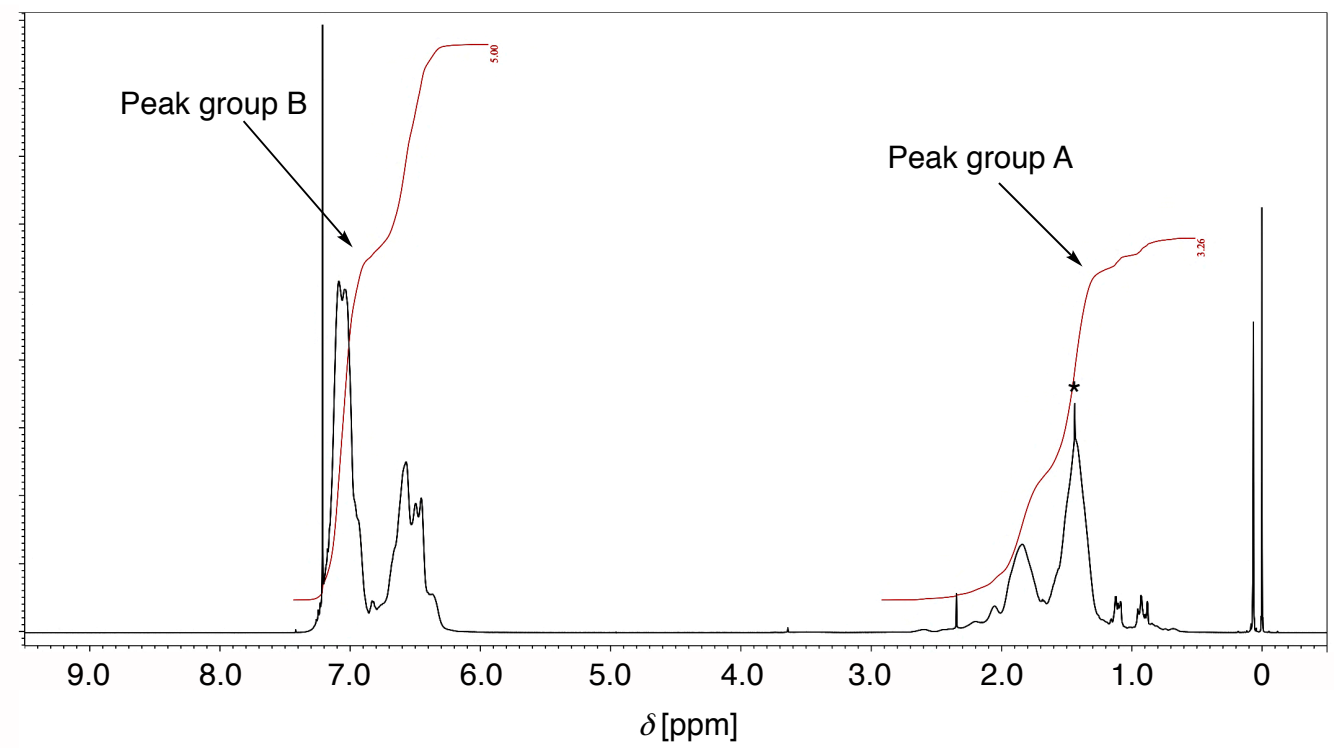

Figure S24. ${ }^{1} \mathrm{H}$ NMR spectrum of $\mathrm{P}(\mathrm{St}-\mathrm{co}-\mathrm{IPOAc})$ in $\mathrm{CDCl}_{3}$.

The peak group A is corresponding to protons a,b,d-f. And, the peak group B is corresponding to protons $\mathbf{c}$. Therefore, copolymerization ratio $(m: n)$ can be estimated as follows:

$$
\begin{gathered}
3.26: 5.00=3 m+8 n: 5 m \\
m: n=97: 3
\end{gathered}
$$

Poor copolymerizability of St and IPOAc was exhibited by both of conversion-based investigation during polymerization and monomer composition analysis of the resulting polymer using ${ }^{1} \mathrm{H}$ NMR spectroscopy. It should be ascribed to the combination of conjugated-type St and unconjugated-type IPOAc, suggesting the advantage of conjugated-type IPBpin as a comonomer for polymerization with St to obtain $\mathrm{P}(\mathrm{MVA}-\mathrm{co}-\mathrm{St})$.

\section{Procedure to determine of monomer reactivity ratios}

Mayo and Lewis described the copolymerization behavior of two monomers $\left(\mathrm{M}_{1}\right.$ and $\mathrm{M}_{2}$ ) by the equation shown below, where $\left[\mathrm{M}_{1}\right]$ is the concentration of $\mathrm{M}_{1},\left[\mathrm{M}_{2}\right]$ is the 
concentration of $\mathrm{M}_{2}, r_{1}$ and $r_{2}$ are the reactivity ratio of $\mathrm{M}_{1}$ and $\mathrm{M}_{2 .}{ }^{1}$

$$
\frac{d\left[M_{1}\right]}{d\left[M_{2}\right]}=\frac{\left[M_{1}\right]\left(r_{1}\left[M_{1}\right]+\left[M_{2}\right]\right)}{\left[M_{2}\right]\left(r_{2}\left[M_{2}\right]+\left[M_{1}\right]\right)}
$$

When the monomer consumptions are small enough, Mayo-Lewis equation shown above can be approximated as

$$
\frac{\Delta\left[M_{1}\right]}{\Delta\left[M_{2}\right]} \fallingdotseq \frac{\left[M_{1}\right]_{0}\left(r_{1}\left[M_{1}\right]_{0}+\left[M_{2}\right]_{0}\right)}{\left[M_{2}\right]_{0}\left(r_{2}\left[M_{2}\right]_{0}+\left[M_{1}\right]_{0}\right)}
$$

where $\left[\mathrm{M}_{1}\right]_{0}$ is the concentration of $\mathrm{M}_{1}$ before reaction, $\left[\mathrm{M}_{2}\right]_{0}$ is the concentration of $\mathrm{M}_{2}$ before reaction, $\Delta\left[\mathrm{M}_{1}\right]$ is the consumption of $\mathrm{M}_{1}$ during reaction, $\Delta\left[\mathrm{M}_{2}\right]$ is the consumption of $\mathrm{M}_{2}$ during reaction.

When we define that $\mathrm{F}_{1}$ is the composition of $\mathrm{M}_{1}$ in the consumed monomers during reaction $\left(\mathrm{F}_{1}=\Delta\left[\mathrm{M}_{1}\right] /\left(\Delta\left[\mathrm{M}_{1}\right]+\Delta\left[\mathrm{M}_{2}\right]\right), \quad \mathrm{F}_{2}=\Delta\left[\mathrm{M}_{2}\right] /\left(\Delta\left[\mathrm{M}_{1}\right]+\Delta\left[\mathrm{M}_{2}\right]\right)\right)$, and $\mathrm{f}_{1}$ is the composition of $\mathrm{M}_{1}$ in monomer feed before reaction $\left(\mathrm{f}_{1}=\left[\mathrm{M}_{1}\right]_{0} /\left(\left[\mathrm{M}_{1}\right]_{0}+\left[\mathrm{M}_{2}\right]_{0}\right), \mathrm{f}_{2}=\right.$ $\left.\left[\mathrm{M}_{2}\right]_{0} /\left(\left[\mathrm{M}_{1}\right]_{0}+\left[\mathrm{M}_{2}\right]_{0}\right)\right)$, equation (2) can be expressed as shown below. ${ }^{2}$

$$
F_{1}=\frac{r_{1} f_{1}^{2}+f_{1}\left(1-f_{1}\right)}{r_{1} f_{1}^{2}+2 f_{1}\left(1-f_{1}\right)+r_{2}\left(1-f_{1}\right)^{2}}
$$

On the basis of equation (3) and the experimental results obtained as $f_{1}$ and $F_{1}$, nonlinear least-squares fitting of $f_{1}$ versus $F_{1}$ was performed by using the Solver Function in Microsoft Office Excel 2011. Sums of the squares of the deviation were minimized by optimizing $r_{1}$ and $r_{2}$. The experimental procedure to obtain $f_{1}$ and $F_{1}$ series in each copolymerization is shown in following section.

Copolymerization of IPBpin and common vinyl comonomers were performed with AIBN by changing the feed ratio ([IPBpin $]_{0}:[\text { comonomer }]_{0}=90: 10,80: 20,70: 30,60: 40$, $50: 50,40: 60,30: 70,20: 80$ and 10:90). Typical procedure of the copolymerization is as follows. A toluene solution of AIBN (1.6 mg, $10 \mu \mathrm{mol})$ was placed in a Schlenk tube 
having PTFE stopcock (J. Young) under Ar atmosphere. Tetralin (13.6 $\mu \mathrm{L}, 13.2 \mathrm{mg}$, $100 \mu \mathrm{mol}$, internal standard), IPBpin $(94.0 \mu \mathrm{L}, 84.0 \mathrm{mg}, 0.50 \mathrm{mmol})$, St $(57.2 \mu \mathrm{L}, 52.1$ $\mathrm{mg}, 0.50 \mathrm{mmol})$ and toluene $(171 \mu \mathrm{L})$ were added at room temperature $(5: 5$ feed ratio condition). The reaction mixture was placed in an oil bath at $60^{\circ} \mathrm{C}$ for $3 \mathrm{~h}$. The reaction was terminated by cooling the solution in a freezer. The composition ratio $[F=$ $\left.D P_{\text {IPBpin }} /\left(D P_{\text {IPBpin }}+D P_{\text {comonomer }}\right)\right]$ was determined from the monomer conversion ratio [Conv.(IPBpin)/(Conv.(IPBpin) + Conv.(comonomer))] by ${ }^{1} \mathrm{H} \mathrm{NMR}\left(\mathrm{CDCl}_{3}\right)$ with tetralin as an internal standard. The actual monomer feed ratio $\left[f=[\text { IPBpin }]_{0} /\left([\text { IPBpin }]_{0}\right.\right.$ $+[\text { comonomer }]_{0}$ ) was also determined by ${ }^{1} \mathrm{H}$ NMR spectrum (before heating). The obtained series of $f_{1}$ and $F_{1}$ were used to determine $r_{1}$ and $r_{2}$ on the basis of equation (3) through non-linear least squares method as mentioned above, affording monomer reactivity ratios shown in the main text. The monomer conversions of each copolymerization are summarized in following tables.

Table S1. Free radical copolymerization of IPBpin $\left(\mathrm{M}_{1}\right)$ with $\mathrm{St}\left(\mathrm{M}_{2}\right)$ for determination of the monomer reactivity ratios a)

\begin{tabular}{ccccc}
\hline$f^{\mathrm{b})}$ & Time $(\mathrm{h})$ & ${\left.\text { Conv.M1 }(\%)^{\mathrm{c}}\right)}$ & Conv.M2 $(\%)^{\mathrm{c})}$ & $\left.F^{\mathrm{d}}\right)$ \\
\hline 0.10 & 3 & 14.1 & 14.1 & 0.10 \\
0.19 & 3 & 7.5 & 13.4 & 0.12 \\
0.30 & 3 & 5.9 & 11.1 & 0.19 \\
0.39 & 3 & 7.9 & 19.3 & 0.21 \\
0.49 & 3 & 4.8 & 11.3 & 0.29 \\
0.59 & 3 & 3.8 & 8.6 & 0.39 \\
0.70 & 3 & 4.0 & 9.6 & 0.48 \\
0.80 & 3 & 4.0 & 16.0 & 0.50 \\
0.90 & 3 & 1.9 & 12.7 & 0.59 \\
\hline
\end{tabular}

a) $\left[\mathrm{M}_{1}+\mathrm{M}_{2}\right]_{0} /[\mathrm{AIBN}]_{0}=2000 / 20 \mathrm{mM}$ in toluene at $60{ }^{\circ} \mathrm{C}$. b) Actual monomer feed ratio $\left(f=\left[\mathrm{M}_{1}\right]_{0} /\left(\left[\mathrm{M}_{1}\right]_{0}+\left[\mathrm{M}_{2}\right]_{0}\right)\right.$ determined by ${ }^{1} \mathrm{H}$ NMR. c) Determined by ${ }^{1} \mathrm{H}$ NMR. $\left.\mathrm{d}\right)$ Calculated from $f$, Conv.M1 and Conv.m2. 
Table S2. Free radical copolymerization of IPBpin $\left(M_{1}\right)$ with MMA $\left(M_{2}\right)$ for determination of the monomer reactivity ratios a)

\begin{tabular}{ccccc}
\hline$f^{\mathrm{b})}$ & Time $(\mathrm{min})$ & ${\left.\text { Conv.M1 }(\%)^{\mathrm{c}}\right)}$ & Conv.M2 $(\%)^{\mathrm{c})}$ & $F^{\mathrm{d})}$ \\
\hline 0.09 & 45 & 6.4 & 13.5 & 0.04 \\
0.19 & 45 & 3.7 & 12.2 & 0.07 \\
0.27 & 45 & 4.1 & 10.2 & 0.13 \\
0.40 & 40 & 4.0 & 9.7 & 0.21 \\
0.54 & 30 & 2.3 & 8.3 & 0.25 \\
0.59 & 30 & 1.8 & 4.8 & 0.35 \\
0.70 & 40 & 2.6 & 10.7 & 0.36 \\
0.81 & 40 & 2.9 & 12.3 & 0.49 \\
0.92 & 40 & 5.4 & 12.6 & 0.84 \\
\hline
\end{tabular}

a) $\left[\mathrm{M}_{1}+\mathrm{M}_{2}\right]_{0} /[\mathrm{AIBN}]_{0}=2000 / 20 \mathrm{mM}$ in toluene at $60{ }^{\circ} \mathrm{C}$. b) Actual monomer feed ratio $\left(f=\left[\mathrm{M}_{1}\right]_{0} /\left(\left[\mathrm{M}_{1}\right]_{0}+\left[\mathrm{M}_{2}\right]_{0}\right)\right.$ determined by ${ }^{1} \mathrm{H}$ NMR. c) Determined by ${ }^{1} \mathrm{H}$ NMR. $\left.\mathrm{d}\right)$ Calculated from $f$, Conv.M1 and Conv. 2 .

Table S3. Free radical copolymerization of IPBpin $\left(M_{1}\right)$ with MA $\left(M_{2}\right)$ for determination of the monomer reactivity ratios ${ }^{\text {a) }}$

\begin{tabular}{ccccc}
\hline$f^{\mathrm{b})}$ & Time $(\mathrm{min})$ & Conv.M1 $\left.(\%)^{\mathrm{c}}\right)$ & Conv.M2 $(\%)^{\mathrm{c})}$ & $F^{\mathrm{d}}$ \\
\hline 0.10 & 10 & 14.2 & 8.6 & 0.15 \\
0.20 & 10 & 8.8 & 9.5 & 0.19 \\
0.31 & 10 & 5.3 & 9.4 & 0.20 \\
0.40 & 10 & 3.7 & 8.2 & 0.23 \\
0.51 & 10 & 3.5 & 11.3 & 0.24 \\
0.61 & 15 & 2.9 & 10.1 & 0.31 \\
0.71 & 10 & 2.3 & 8.2 & 0.40 \\
0.80 & 10 & 1.9 & 7.5 & 0.50 \\
0.92 & 15 & 1.8 & 9.2 & 0.69 \\
\hline
\end{tabular}

a) $\left[\mathrm{M}_{1}+\mathrm{M}_{2}\right]_{0} /[\mathrm{AIBN}]_{0}=2000 / 20 \mathrm{mM}$ in toluene at $60{ }^{\circ} \mathrm{C}$. b) Actual monomer feed ratio $\left(f=\left[\mathrm{M}_{1}\right]_{0} /\left(\left[\mathrm{M}_{1}\right]_{0}+\left[\mathrm{M}_{2}\right]_{0}\right)\right.$ determined by ${ }^{1} \mathrm{H}$ NMR. c) Determined by ${ }^{1} \mathrm{H}$ NMR. $\left.\mathrm{d}\right)$ Calculated from $f$, Conv.M1 and Conv.M2. 
Table S4. Free radical copolymerization of IPBpin $\left(\mathrm{M}_{1}\right)$ with AN $\left(\mathrm{M}_{2}\right)$ for determination of the monomer reactivity ratios a)

\begin{tabular}{ccccc}
\hline$f^{\mathrm{b})}$ & Time $(\mathrm{min})$ & Conv.M1 $\left.(\%)^{\mathrm{c}}\right)$ & Conv.M2 $(\%)^{\mathrm{c})}$ & $F^{\mathrm{d})}$ \\
\hline 0.11 & 15 & 3.8 & 7.7 & 0.06 \\
0.21 & 30 & 5.0 & 9.2 & 0.13 \\
0.32 & 30 & 2.1 & 6.4 & 0.14 \\
0.42 & 30 & 2.2 & 5.5 & 0.22 \\
0.53 & 30 & 2.5 & 7.5 & 0.28 \\
0.64 & 45 & 3.7 & 7.2 & 0.47 \\
0.73 & 45 & 5.3 & 13.7 & 0.52 \\
0.82 & 60 & 5.3 & 18.0 & 0.58 \\
0.92 & 60 & 3.8 & 24.9 & 0.64 \\
\hline
\end{tabular}

a) $\left[\mathrm{M}_{1}+\mathrm{M}_{2}\right]_{0} /[\mathrm{AIBN}]_{0}=2000 / 20 \mathrm{mM}$ in toluene at $60{ }^{\circ} \mathrm{C}$. b) Actual monomer feed ratio $\left(f=\left[\mathrm{M}_{1}\right]_{0} /\left(\left[\mathrm{M}_{1}\right]_{0}+\left[\mathrm{M}_{2}\right]_{0}\right)\right.$ determined by ${ }^{1} \mathrm{H}$ NMR. c) Determined by ${ }^{1} \mathrm{H}$ NMR. $\left.\mathrm{d}\right)$ Calculated from $f$, Conv.M1 and Conv.M2.

Table S5. Free radical copolymerization of IPBpin $\left(M_{1}\right)$ with EMI $\left(M_{2}\right)$ for determination of the monomer reactivity ratios a)

\begin{tabular}{ccccc}
\hline$f^{\mathrm{b})}$ & Time $(\mathrm{min})$ & ${\left.\text { Conv.M1 }(\%)^{\mathrm{c}}\right)}$ Conv.M2 $(\%)^{\mathrm{c})}$ & $F^{\mathrm{d})}$ \\
\hline 0.09 & 10 & 15.1 & 4.1 & 0.27 \\
0.19 & 10 & 21.2 & 9.0 & 0.35 \\
0.27 & 10 & 12.3 & 8.3 & 0.35 \\
0.39 & 5 & 5.2 & 5.5 & 0.38 \\
0.50 & 10 & 8.9 & 9.7 & 0.48 \\
0.61 & 10 & 8.7 & 12.5 & 0.52 \\
0.71 & 10 & 5.2 & 11.6 & 0.52 \\
0.80 & 10 & 4.2 & 15.4 & 0.53 \\
0.91 & 5 & 1.2 & 9.0 & 0.56 \\
\hline
\end{tabular}

a) $\left[\mathrm{M}_{1}+\mathrm{M}_{2}\right]_{0} /[\mathrm{AIBN}]_{0}=2000 / 20 \mathrm{mM}$ in toluene at $60{ }^{\circ} \mathrm{C}$. b) Actual monomer feed ratio $\left(f=\left[\mathrm{M}_{1}\right]_{0} /\left(\left[\mathrm{M}_{1}\right]_{0}+\left[\mathrm{M}_{2}\right]_{0}\right)\right.$ determined by ${ }^{1} \mathrm{H}$ NMR. c) Determined by ${ }^{1} \mathrm{H}$ NMR. $\left.\mathrm{d}\right)$ Calculated from $f$, Conv.M1 and Conv.M2. 
Table S6. Free radical copolymerization of IPBpin $\left(\mathrm{M}_{1}\right)$ with $\operatorname{IBVE}\left(\mathrm{M}_{2}\right)$ for determination of the monomer reactivity ratios a)

\begin{tabular}{ccccc}
\hline$f^{\mathrm{b})}$ & Time $(\mathrm{h})$ & ${\left.\text { Conv.M1 }(\%)^{\mathrm{c}}\right)}$ & Conv.M2 $(\%)^{\mathrm{c})}$ & $F^{\mathrm{d})}$ \\
\hline 0.10 & 7 & 13.6 & 7.7 & 0.17 \\
0.20 & 7 & 13.2 & 6.5 & 0.33 \\
0.30 & 7 & 11.5 & 5.7 & 0.46 \\
0.37 & 7 & 13.3 & 6.5 & 0.55 \\
0.53 & 7 & 13.4 & 6.0 & 0.71 \\
0.64 & 7 & 15.4 & 10.5 & 0.72 \\
0.73 & 7 & 17.9 & 10.2 & 0.83 \\
0.82 & 3 & 8.3 & 6.7 & 0.85 \\
0.91 & 3 & 10.6 & 14.6 & 0.88 \\
\hline
\end{tabular}

a) $\left[\mathrm{M}_{1}+\mathrm{M}_{2}\right]_{0} /[\mathrm{AIBN}]_{0}=2000 / 20 \mathrm{mM}$ in toluene at $60{ }^{\circ} \mathrm{C}$. b) Actual monomer feed ratio $\left(f=\left[\mathrm{M}_{1}\right]_{0} /\left(\left[\mathrm{M}_{1}\right]_{0}+\left[\mathrm{M}_{2}\right]_{0}\right)\right.$ determined by ${ }^{1} \mathrm{H}$ NMR. c) Determined by ${ }^{1} \mathrm{H}$ NMR. $\left.\mathrm{d}\right)$ Calculated from $f$, Conv.M1 and Conv.M2.

\section{Oxidation of P(IPBpin-co-St) obtained by free radical copolymerization of IPBpin and St}

This reaction was carried out under air. The obtained P(IPBpin-co-St) $500 \mathrm{mg}$ was dissolved to THF (141.5 mL). Ethanol (15.2 mL), an aqueous solution of $\mathrm{NaOH}(6 \mathrm{M}$, $15.2 \mathrm{~mL})$, and an aqueous solution of $\mathrm{H}_{2} \mathrm{O}_{2}(35 \mathrm{wt} \%, 30.5 \mathrm{~mL})$ were added. The reaction solution was stirred at room temperature for 24 hours. The reaction solution was neutralized using $\mathrm{HCl}$ aq. The volume of the solution was reduced to $100 \mathrm{~mL}$ by evaporation. The resulting solution was purified by dialysis (MWCO:1000, water/THF $=50 / 50 \rightarrow$ water $/ \mathrm{THF}=30 / 70 \rightarrow \mathrm{THF})$. After evaporation, the residue was purified by preparative SEC. After evaporation, $\operatorname{poly}(\alpha$-methyl vinyl alcohol-co-styrene) (P(MVA-co-St), colorless solid, $198 \mathrm{mg}$ ) was obtained. 
Scheme S9. Oxidation of boronyl groups of P(IPBpin-co-St)
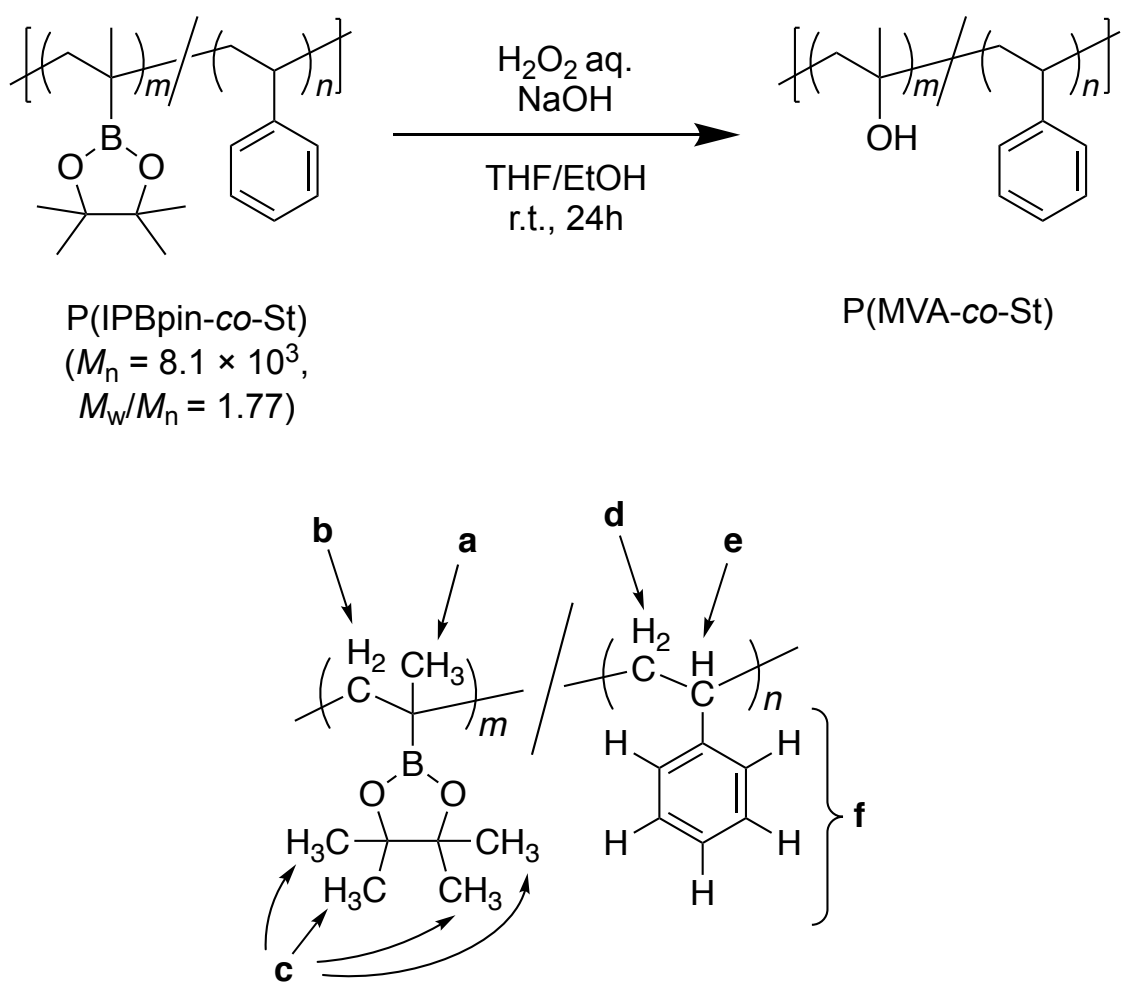

Figure S25. The molecular structure of $\mathrm{P}(\mathrm{IPBpin}-\mathrm{co}-\mathrm{St})$ with its ${ }^{1} \mathrm{H}$ NMR assignment.

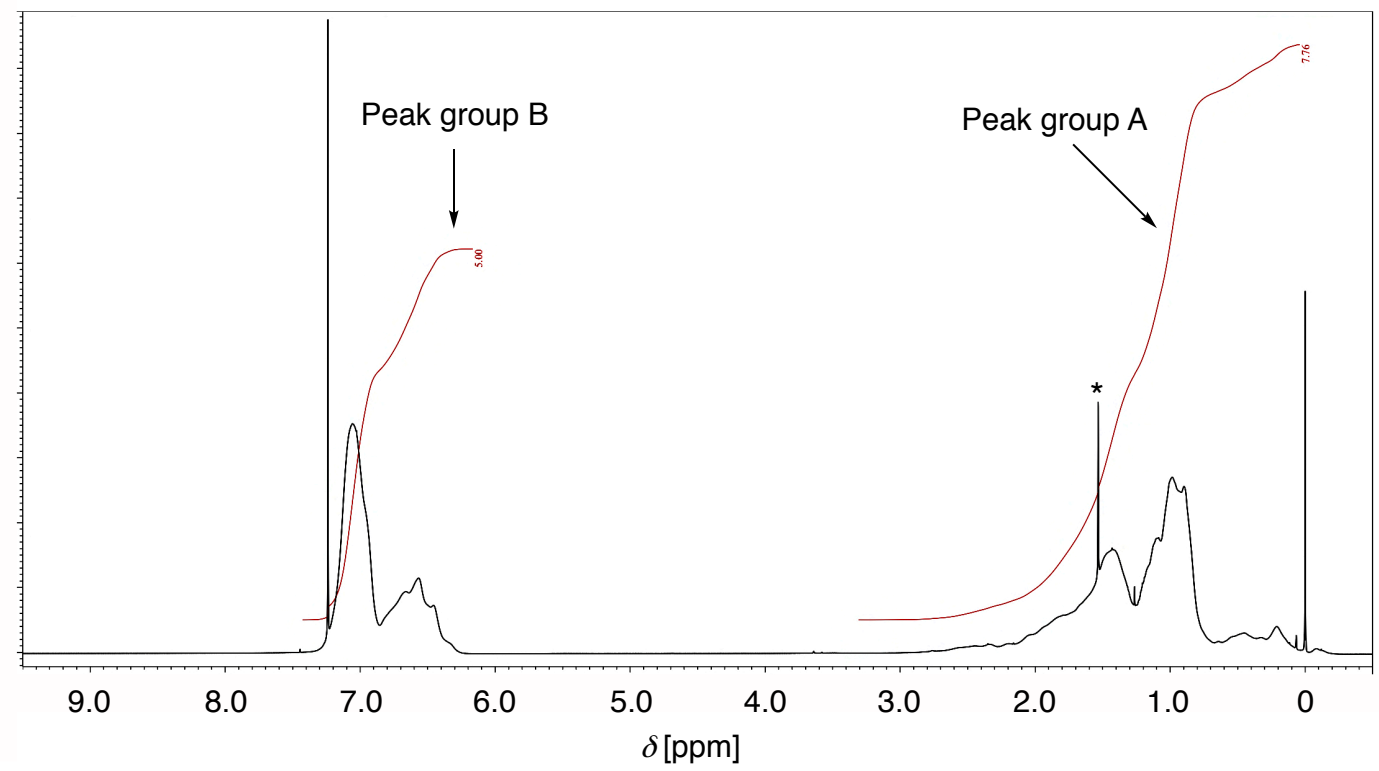

Figure S26. ${ }^{1} \mathrm{H}$ NMR spectrum of $\mathrm{P}(\mathrm{IPBpin}-\mathrm{co}-\mathrm{St})$ in $\mathrm{CDCl}_{3}$. 
The peak group A is corresponding to protons a-e. The peak group B is corresponding to protons f. Therefore, monomer unit ratio $(m: n)$ can be estimated as follows:

$$
\begin{gathered}
7.76: 5.00=17 m+3 n: 5 n \\
m: n=22: 78
\end{gathered}
$$

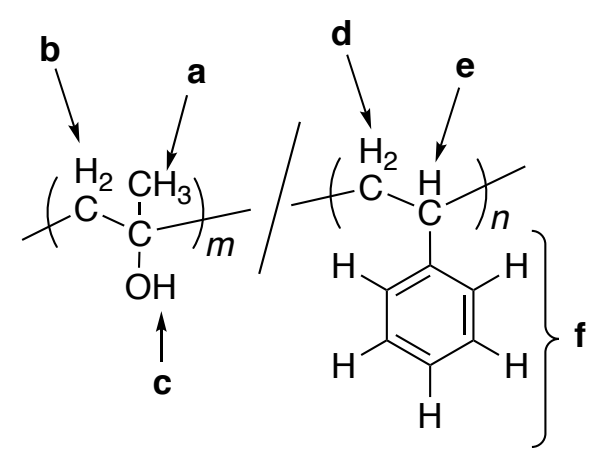

Figure S27. The molecular structure of $\mathrm{P}(\mathrm{MVA}-\mathrm{co}-\mathrm{St})$ with its ${ }^{1} \mathrm{H}$ NMR assignment.

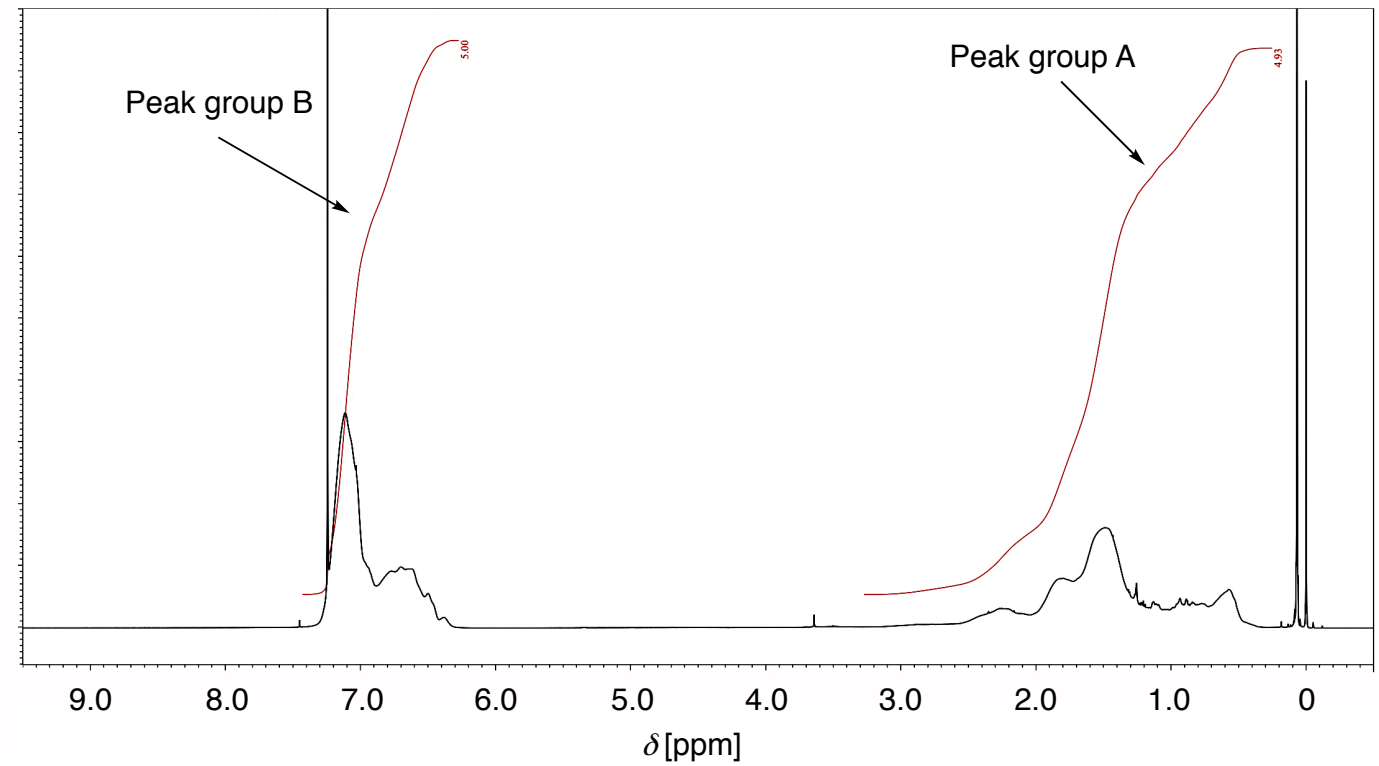

Figure S28. ${ }^{1} \mathrm{H}$ NMR spectrum of $\mathrm{P}(\mathrm{MVA}-\mathrm{co}-\mathrm{St})$ in $\mathrm{CDCl}_{3}$.

The peak group A is corresponding to protons a-e. The peak group B is corresponding to protons $\mathbf{f}$. Therefore, monomer unit ratio $(m: n)$ can be estimated as follows:

$$
4.93: 5.00=6 m+3 n: 5 n
$$




$$
m: n=24: 76
$$

The monomer unit ratio $(m: n)$ of $\mathrm{P}(\mathrm{MVA}-\mathrm{co}-\mathrm{St})$ was similar to that of $\mathrm{P}(\mathrm{IPBpin}-\mathrm{co}-\mathrm{St})$, supported that the quantitative oxidation proceeded.

We furthermore measured ${ }^{1} \mathrm{H}$ NMR spectrum of $\mathrm{P}(\mathrm{MVA}-\mathrm{co}-\mathrm{St})$ in the use of DMSO- $d_{6}$ as the solvent to detect a hydroxy proton as a separated peak.

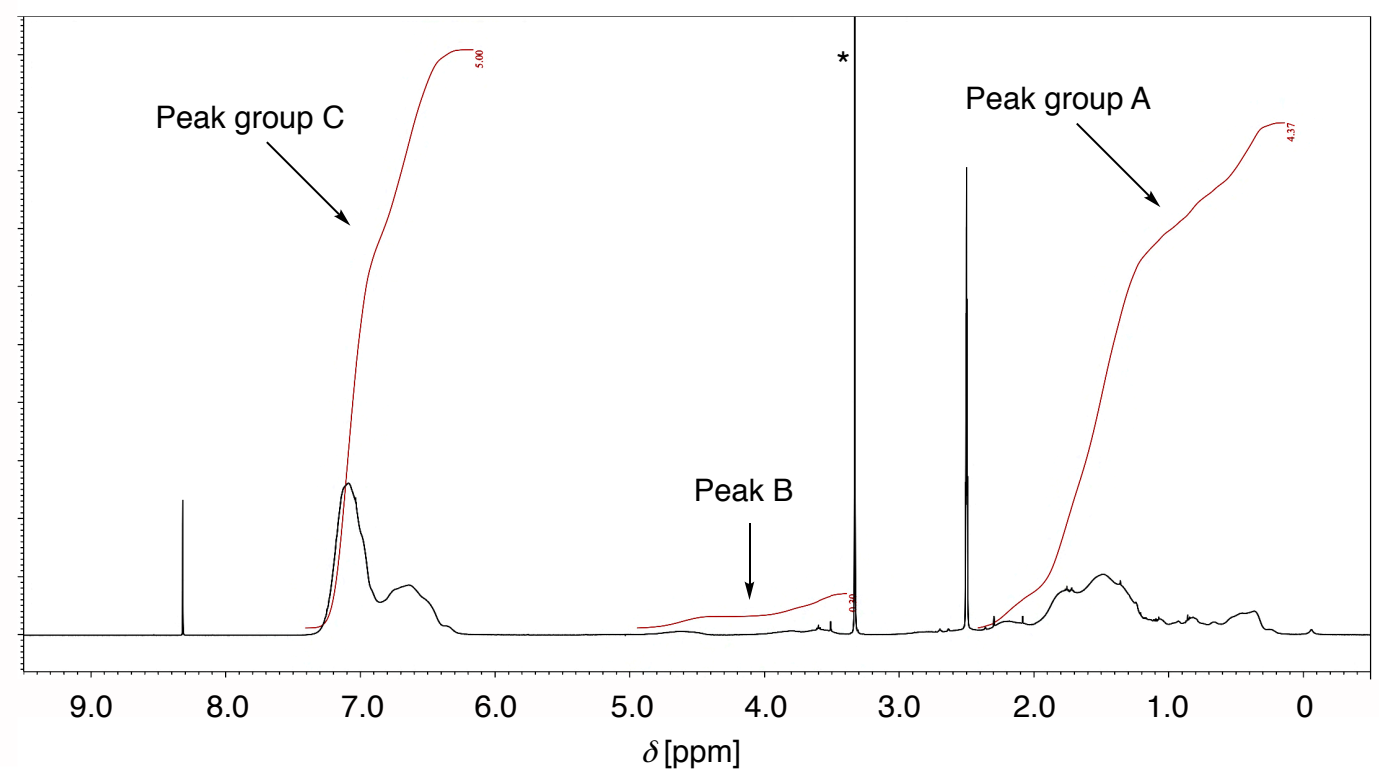

Figure S29. ${ }^{1} \mathrm{H}$ NMR spectrum of $\mathrm{P}(\mathrm{MVA}-\mathrm{co}-\mathrm{St})$ in $\mathrm{CDCl}_{3}$.

The peak group A is corresponding to protons a,b,d,e. The peak B is corresponding to protons c. The peak group $\mathrm{C}$ is corresponding to protons $\mathbf{f}$. Therefore, monomer unit ratio $(m: n)$ can be estimated as follows:

$$
\begin{gathered}
0.30: 5.00=n: 5 m \\
m: n=23: 77
\end{gathered}
$$

This monomer unit ratio is substantially identical to the one of $\mathrm{P}(\mathrm{IPBpin}-\mathrm{co}-\mathrm{St})$. This result also supported that almost quantitative oxidation proceeded. 


\section{Solubility Test of Obtained Polymers}

The basic solubilities of obtained polymers (P(IPBpin-co-St), P(MVA-co-St) and PSt) were tested in the use of cyclohexane, dichloromethane, dimethyl sulfoxide and water as the solvent. Solvent (about $1 \mathrm{~mL}$ ) was mixed with the polymer (about $2 \mathrm{mg}$ ) in a glass vial, and then allowed to stand at RT. About several hours, the content of the vial was checked by eye-sight to judge the solubility. 


\section{Thermal Property of Obtained Polymers}

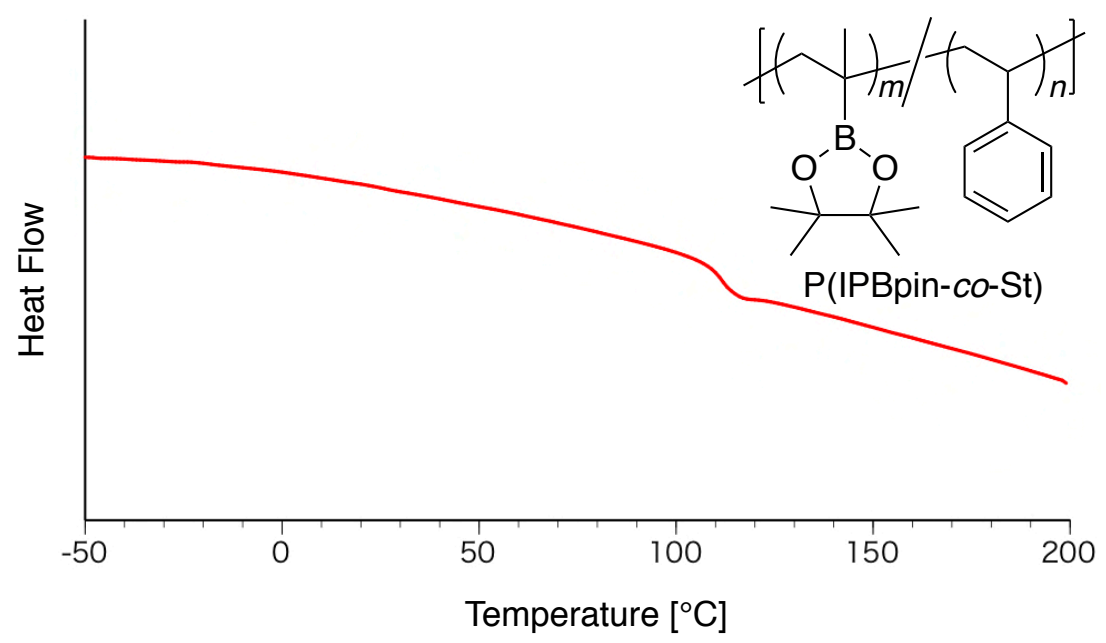

Figure S30. DSC curve of the $\mathrm{P}(\mathrm{IPBpin}-\mathrm{co}-\mathrm{St})$ obtained through free radical copolymerization $\left(M_{\mathrm{n}}=8.8 \times 10^{3}, M_{\mathrm{w}} / M_{\mathrm{n}}=1.80,3.3 \mathrm{mg}\right.$; heating from -50 to $200{ }^{\circ} \mathrm{C}$; rate $\left.=10^{\circ} \mathrm{C} / \mathrm{min}\right)$.

Based on the DSC curve, glass-transition temperature $\left(T_{\mathrm{g}}\right)$ of $\mathrm{P}(\mathrm{IPBpin}-\mathrm{co}-\mathrm{St})$ was judged as $107^{\circ} \mathrm{C}$.

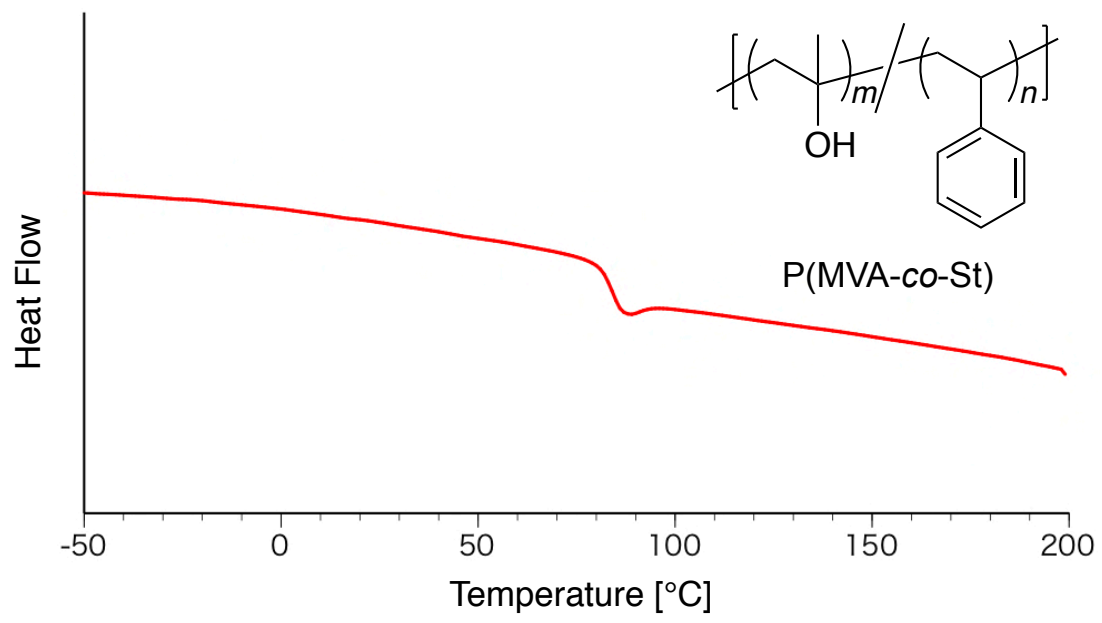

Figure S31. DSC curve of the $\mathrm{P}(\mathrm{MVA}-\mathrm{co}-\mathrm{St})$ obtained through free radical copolymerization $\left(4.5 \mathrm{mg}\right.$; heating from -50 to $200{ }^{\circ} \mathrm{C}$; rate $=10{ }^{\circ} \mathrm{C} / \mathrm{min}$ ).

Based on the DSC curve, $T_{\mathrm{g}}$ of $\mathrm{P}(\mathrm{MVA}-\mathrm{co}-\mathrm{St})$ was judged as $81^{\circ} \mathrm{C}$. 


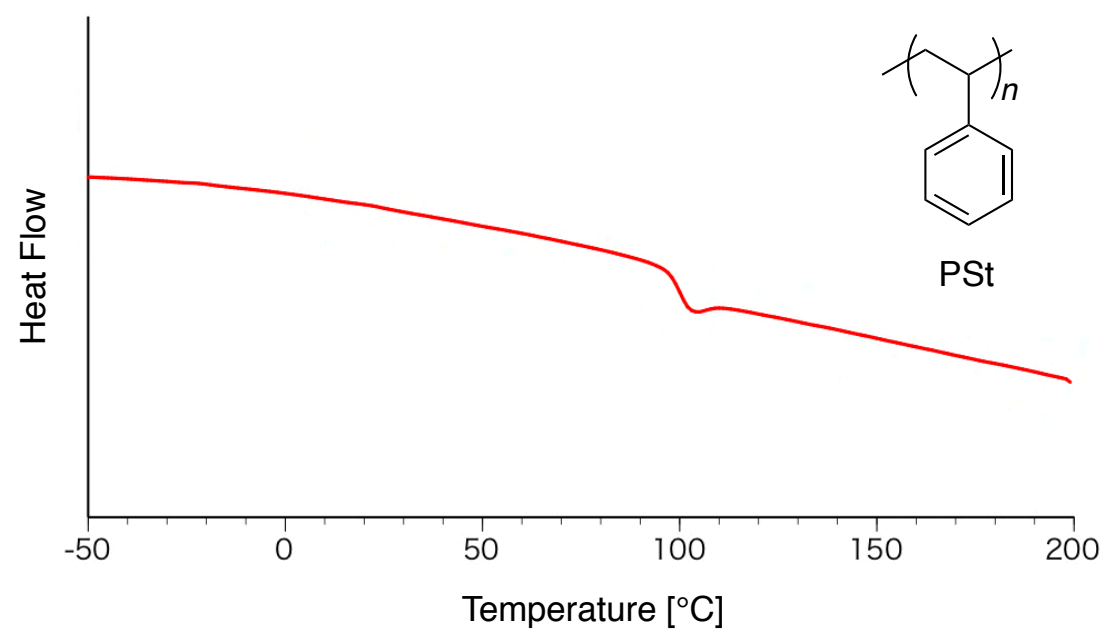

Figure S32. DSC curve of the PSt obtained through free radical copolymerization $\left(M_{\mathrm{n}}=\right.$ $11.2 \times 10^{3}, M_{\mathrm{w}} / M_{\mathrm{n}}=1.76,3.3 \mathrm{mg}$; heating from -50 and $200{ }^{\circ} \mathrm{C}$; rate $=10^{\circ} \mathrm{C} / \mathrm{min}$ ).

Based on the DSC curve, $T_{\mathrm{g}}$ of PSt was judged as $97^{\circ} \mathrm{C}$.

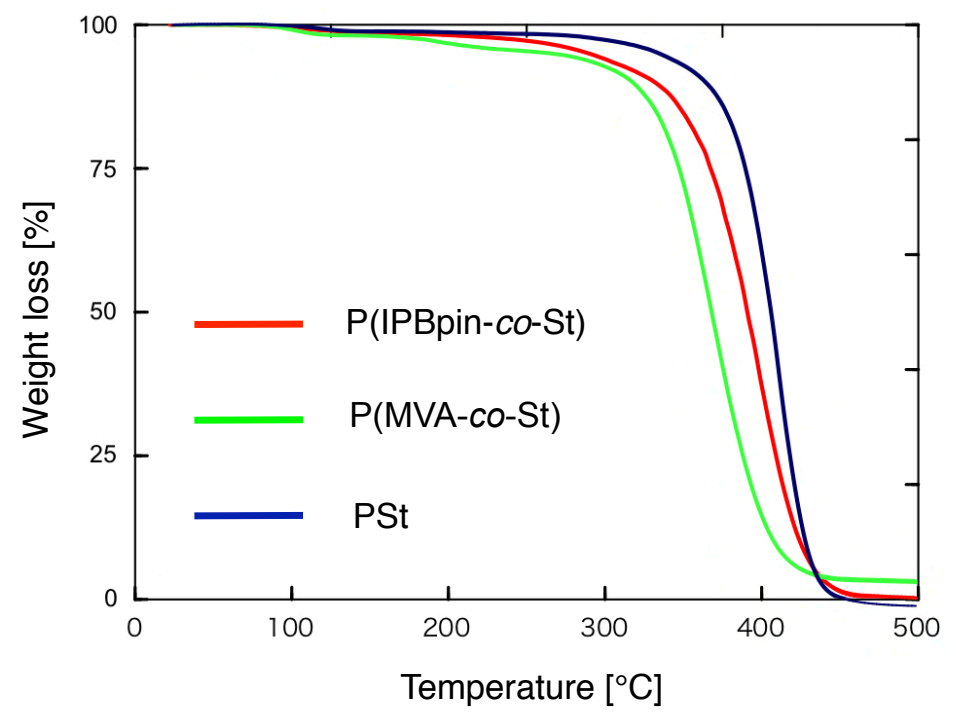

Figure S33. TGA curves of $\mathrm{P}(\mathrm{IPBpin}-\mathrm{co}-\mathrm{St})\left(\right.$ red; $\left.M_{\mathrm{n}}=8.8 \times 10^{3}, M_{\mathrm{w}} / M_{\mathrm{n}}=1.80\right)$, $\mathrm{P}(\mathrm{MVA}-c o-\mathrm{St})$ (green) and PSt (blue; $M_{\mathrm{n}}=11.2 \times 10^{3}, M_{\mathrm{w}} / M_{\mathrm{n}}=1.76$ ) (heating from 20 to $500{ }^{\circ} \mathrm{C}$; rate $=10^{\circ} \mathrm{C} / \mathrm{min}$ ). 
Table S7. 10\% weight loss temperature of P(IPBpin-co-St), P(MVA-co-St) and PSt

\begin{tabular}{cccc}
\hline Copolymer & $\mathrm{P}(\mathrm{IPBpin}-\mathrm{co}-\mathrm{St})$ & $\mathrm{P}(\mathrm{MVA}-\mathrm{co}-\mathrm{St})$ & $\mathrm{PSt}$ \\
\hline$T_{10 \% \text { weight loss }}\left({ }^{\circ} \mathrm{C}\right)$ & 331 & 316 & 363 \\
\hline
\end{tabular}

\section{Controlled Radical Copolymerization of IPBpin with St}

Radical copolymerization of IPBpin with St in the presence of CPDT: A Schlenk tube was filled with Ar. A toluene solution of AIBN (10 mg/mL, $394 \mu \mathrm{L}, 24.0 \mu \mathrm{moL})$, tetralin $(40.9 \mu \mathrm{L}, 39.7 \mathrm{mg}, 300 \mu \mathrm{mol}$, internal standard), CPDT (10.5 $\mu \mathrm{L}, 10.4 \mathrm{mg}, 30.0$ $\mu \mathrm{mol})$, IPBpin $(282 \mu \mathrm{L}, 252 \mathrm{mg}, 1.50 \mathrm{mmol})$, St (172 $\mu \mathrm{L}, 156 \mathrm{mg}, 1.50 \mathrm{mmol})$, and toluene $(601 \mu \mathrm{L})$ were added. The reaction mixture was stirred at $60{ }^{\circ} \mathrm{C}$ in an oil bath. The polymerization was monitored by ${ }^{1} \mathrm{H}$ NMR and SEC. After $48 \mathrm{~h}$, IPBpin and St conversion reached to $31 \%$ and $66 \%$ respectively.

Scheme S10. Radical copolymerization of IPBpin with St in the presence of CPDT

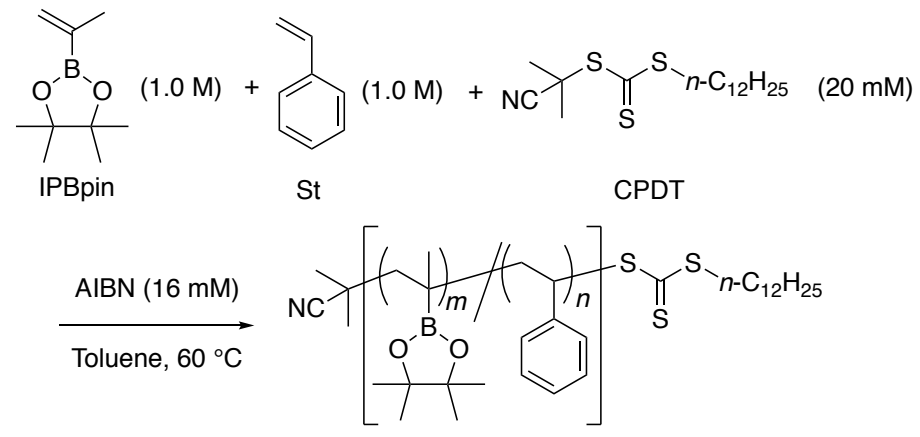

Table S8. Conversion of RAFT copolymerization of IPBpin with St and SEC-based molecular weight of the resultant copolymer

\begin{tabular}{ccccc}
\hline Time [h] & IPBpin Conv. [\%] & St Conv. [\%] & $M_{\mathrm{n}}\left[10^{3}\right]$ & $M_{\mathrm{w}} / M_{\mathrm{n}}$ \\
\hline 2 & 3.0 & 5.5 & 0.71 & 1.13 \\
24 & 23.9 & 51.7 & 2.81 & 1.23 \\
48 & 31.1 & 66.0 & 3.39 & 1.24 \\
\hline
\end{tabular}




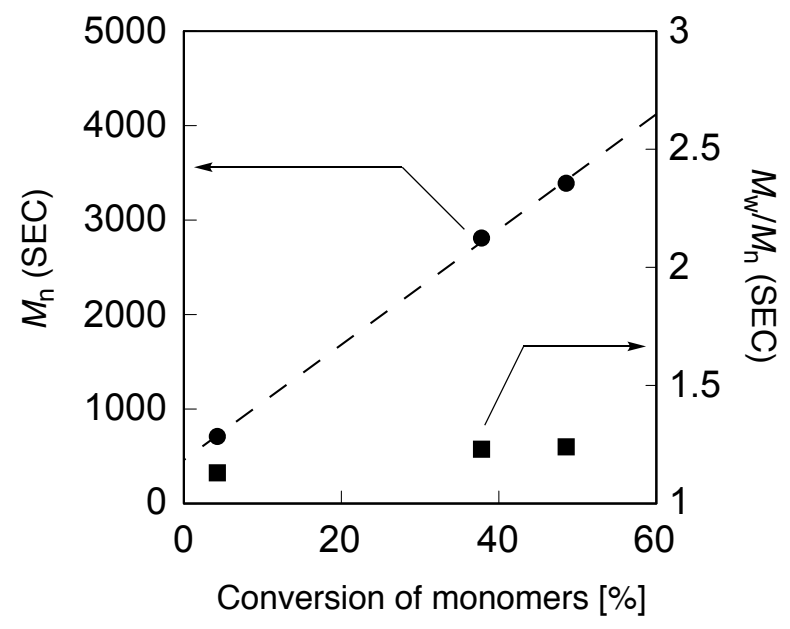

Figure S34. The correlation between $M_{\mathrm{n}}$ or $M_{\mathrm{w}} / M_{\mathrm{n}}$ and conversion of monomers (IPBpin and St) during RAFT copolymerization

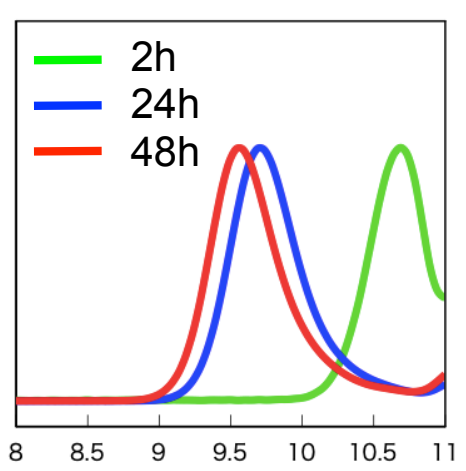

Figure S35. Time-dependent SEC traces of RAFT copolymerization of IPBpin and St.

Based on the low $M_{\mathrm{w}} / M_{\mathrm{n}}$ values, unimodal shape of SEC peaks showing the shift to high molecular weight side with progress of the polymerization, and linear relationship between $M_{\mathrm{n}}$ and monomer conversion, we judged that radical copolymerization of IPBpin and St could be controlled by using RAFT reageant.

\section{Computational Study for Radical Copolymerization Behavior}

Computational investigation of copolymerization behavior: The Gaussian 16A.03 program package ${ }^{3}$ was used for computation. The density functional theory (DFT) was 
applied for the optimization of the structures and vibrational analysis at B3LYP/6-31G* level. Standard orientation of optimized molecular structure and SOMO level are shown below in each radical species.

Radical species of St

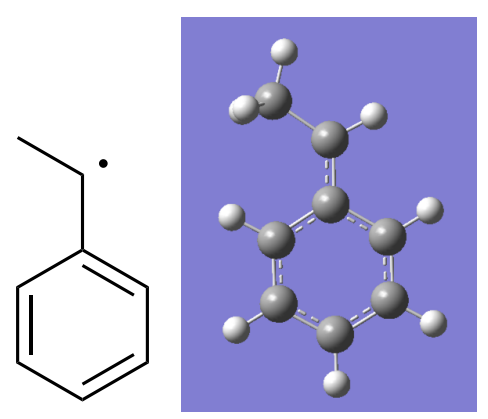

SOMO energy $(\mathrm{eV})=-0.16957$

Standard orientation:

\begin{tabular}{rrrrrr} 
Center & Atomic & Atomic & \multicolumn{2}{c}{ Coordinates (Angstroms) } \\
Number & Number & Type & $\mathrm{X}$ & $\mathrm{Y}$ & $\mathrm{Z}$ \\
\hline 1 & 6 & 0 & -2.965478 & 0.332499 & -0.000076 \\
2 & 1 & 0 & -2.942577 & 0.992020 & 0.880733 \\
3 & 1 & 0 & -3.931013 & -0.181321 & -0.000188 \\
4 & 1 & 0 & -2.942502 & 0.992262 & -0.880702 \\
5 & 6 & 0 & -1.833018 & -0.646844 & -0.000162 \\
6 & 6 & 0 & -0.461521 & -0.295893 & -0.000059 \\
7 & 1 & 0 & -2.076274 & -1.706817 & -0.000316 \\
8 & 6 & 0 & -0.015494 & 1.057693 & 0.000143 \\
9 & 6 & 0 & 0.541063 & -1.309519 & -0.000155 \\
10 & 6 & 0 & 1.889675 & -0.990746 & -0.000057 \\
11 & 6 & 0 & 1.337779 & 1.365901 & 0.000240 \\
12 & 6 & 0 & 2.302072 & 0.349644 & 0.000141 \\
13 & 1 & 0 & 0.228452 & -2.351346 & -0.000309 \\
14 & 1 & 0 & 2.631186 & -1.785764 & -0.000135
\end{tabular}




$\begin{array}{rrrrrr}15 & 1 & 0 & -0.747919 & 1.859612 & 0.000222 \\ 16 & 1 & 0 & 1.650478 & 2.407233 & 0.000393 \\ 17 & 1 & 0 & 3.359704 & 0.597703 & 0.000218\end{array}$

Radical species of VOAc

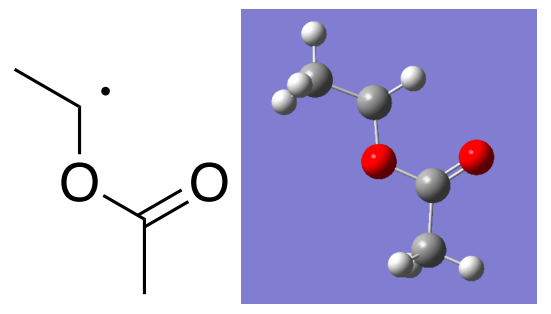

SOMO energy $(e V)=-0.17985$

Standard orientation:

\begin{tabular}{rrrrrr} 
Center & Atomic & Atomic & \multicolumn{2}{c}{ Coordinates (Angstroms) } \\
Number & Number & Type & $\mathrm{X}$ & $\mathrm{Y}$ & $\mathrm{Z}$ \\
\hline 1 & 6 & 0 & -2.618597 & -0.312464 & 0.062652 \\
2 & 1 & 0 & -3.447183 & 0.360102 & -0.180613 \\
3 & 1 & 0 & -2.763509 & -0.656000 & 1.101897 \\
4 & 1 & 0 & -2.693613 & -1.199460 & -0.579351 \\
5 & 6 & 0 & -1.325184 & 0.386359 & -0.131108 \\
6 & 8 & 0 & -0.211791 & -0.425570 & -0.059967 \\
7 & 1 & 0 & -1.153850 & 1.439250 & 0.053614 \\
8 & 6 & 0 & 1.025427 & 0.162137 & 0.004440 \\
9 & 8 & 0 & 1.193193 & 1.358702 & 0.036013 \\
10 & 6 & 0 & 2.103630 & -0.891838 & 0.020261 \\
11 & 1 & 0 & 1.931320 & -1.604378 & 0.833336 \\
12 & 1 & 0 & 2.088792 & -1.457538 & -0.917910 \\
13 & 1 & 0 & 3.075168 & -0.412197 & 0.143188
\end{tabular}


Radical species of IPBpin

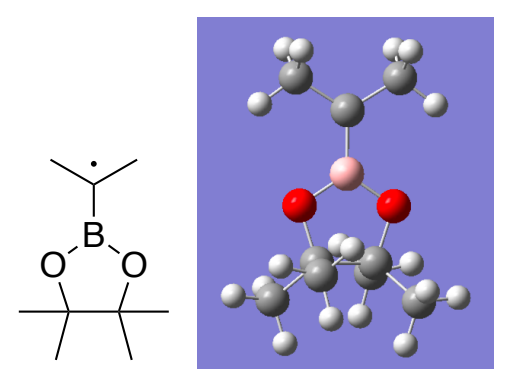

SOMO energy $(e V)=-0.18782$

Standard orientation:

\begin{tabular}{|c|c|c|c|c|c|}
\hline \multirow{2}{*}{$\begin{array}{l}\text { Center } \\
\text { Number }\end{array}$} & \multirow{2}{*}{$\begin{array}{l}\text { Atomic } \\
\text { Number }\end{array}$} & \multirow{2}{*}{$\begin{array}{l}\text { Atomic } \\
\text { Type }\end{array}$} & \multicolumn{3}{|c|}{ Coordinates (Angstroms) } \\
\hline & & & $X$ & $\mathrm{Y}$ & Z \\
\hline 1 & 6 & 0 & -3.241057 & -1.256404 & -0.236434 \\
\hline 2 & 6 & 0 & -2.457362 & 0.000000 & 0.000000 \\
\hline 3 & 1 & 0 & -3.908034 & -1.477545 & 0.613082 \\
\hline 4 & 1 & 0 & -3.901391 & -1.156904 & -1.113549 \\
\hline 5 & 1 & 0 & -2.594873 & -2.124211 & -0.395116 \\
\hline 6 & 6 & 0 & -3.241057 & 1.256404 & 0.236434 \\
\hline 7 & 5 & 0 & -0.925149 & 0.000000 & 0.000000 \\
\hline 8 & 1 & 0 & -3.908030 & 1.477548 & -0.613084 \\
\hline 9 & 1 & 0 & -3.901396 & 1.156901 & 1.113546 \\
\hline 10 & 1 & 0 & -2.594873 & 2.124210 & 0.395122 \\
\hline 11 & 8 & 0 & -0.156539 & -1.123255 & -0.245262 \\
\hline 12 & 8 & 0 & -0.156539 & 1.123255 & 0.245261 \\
\hline 13 & 6 & 0 & 1.221947 & -0.787122 & 0.063003 \\
\hline 14 & 6 & 0 & 1.221947 & 0.787122 & -0.063003 \\
\hline 15 & 6 & 0 & 1.489501 & 1.282363 & -1.491702 \\
\hline 16 & 6 & 0 & 2.131092 & -1.519523 & -0.922820 \\
\hline 17 & 6 & 0 & 1.489500 & -1.282363 & 1.491702 \\
\hline
\end{tabular}




$\begin{array}{llllll}18 & 6 & 0 & 2.131092 & 1.519524 & 0.922821 \\ 19 & 1 & 0 & 1.866944 & 1.294969 & 1.958686 \\ 20 & 1 & 0 & 3.181396 & 1.249632 & 0.762667 \\ 21 & 1 & 0 & 2.033910 & 2.600346 & 0.777566 \\ 22 & 1 & 0 & 2.533116 & 1.128603 & -1.786346 \\ 23 & 1 & 0 & 0.845486 & 0.773329 & -2.215782 \\ 24 & 1 & 0 & 1.271823 & 2.353819 & -1.541465 \\ 25 & 1 & 0 & 2.033911 & -2.600346 & -0.777564 \\ 26 & 1 & 0 & 1.866944 & -1.294970 & -1.958685 \\ 27 & 1 & 0 & 3.181396 & -1.249631 & -0.762667 \\ 28 & 1 & 0 & 0.845487 & -0.773328 & 2.215782 \\ 29 & 1 & 0 & 1.271819 & -2.353819 & 1.541465 \\ 30 & 1 & 0 & 2.533116 & -1.128606 & 1.786346\end{array}$

Radical species of MMA

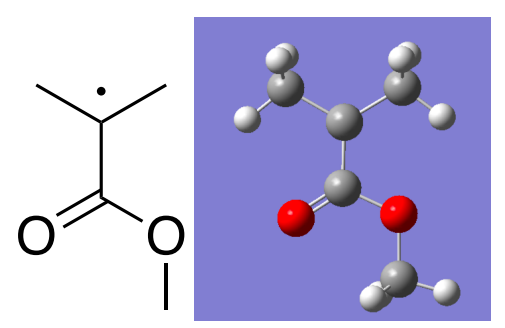

SOMO energy $(\mathrm{eV})=-0.21076$

Standard orientation:

\begin{tabular}{|c|c|c|c|c|c|}
\hline Center & Atomic & Atomic & \multicolumn{3}{|c|}{ Coordinates (Angstroms) } \\
\hline Number & Number & Type & $\mathrm{X}$ & Y & \\
\hline 1 & 6 & 0 & -1.090342 & 0.119465 & -0.000003 \\
\hline 2 & 6 & 0 & -2.180832 & -0.900577 & 0.000004 \\
\hline 3 & 6 & 0 & -1.449299 & 1.570195 & -0.000007 \\
\hline
\end{tabular}




$\begin{array}{rrrrrr}4 & 6 & 0 & 0.287625 & -0.350681 & -0.000002 \\ 5 & 1 & 0 & -2.831495 & -0.779196 & -0.879266 \\ 6 & 1 & 0 & -1.772032 & -1.912313 & -0.000032 \\ 7 & 1 & 0 & -2.831439 & -0.779242 & 0.879322 \\ 8 & 1 & 0 & -2.065333 & 1.817005 & -0.878215 \\ 9 & 1 & 0 & -2.064633 & 1.817184 & 0.878646 \\ 10 & 1 & 0 & -0.570174 & 2.214920 & -0.000408 \\ 11 & 8 & 0 & 0.621974 & -1.530437 & -0.000004 \\ 12 & 8 & 0 & 1.200237 & 0.664342 & 0.000002 \\ 13 & 6 & 0 & 2.568780 & 0.244220 & 0.000003 \\ 14 & 1 & 0 & 2.791901 & -0.353871 & 0.888418 \\ 15 & 1 & 0 & 2.791898 & -0.353883 & -0.888405 \\ 16 & 1 & 0 & 3.158023 & 1.162424 & -0.000004 \\ --------------- & & \end{array}$

Radical species of MA

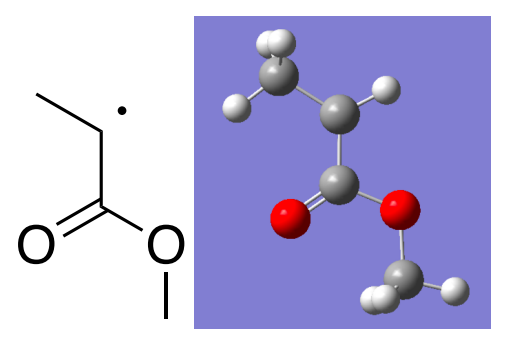

SOMO energy $(\mathrm{eV})=-0.22801$

Standard orientation:

$\begin{array}{rrrrrr}\begin{array}{l}\text { Center } \\ \text { Number }\end{array} & \begin{array}{c}\text { Atomic } \\ \text { Number }\end{array} & \begin{array}{r}\text { Atomic } \\ \text { Type }\end{array} & \mathrm{X} & \mathrm{Y} & \mathrm{Z} \\ -\mathrm{y} & 6 & 0 & -2.533087 & 0.007013 & 0.000000 \\ 2 & 1 & 0 & -3.127458 & -0.283882 & 0.878996 \\ 3 & 6 & 0 & -1.211221 & -0.668462 & 0.000000\end{array}$




$\begin{array}{rrrrrc}4 & 1 & 0 & -3.127463 & -0.283890 & -0.878990 \\ 5 & 1 & 0 & -2.409707 & 1.092470 & -0.000005 \\ 6 & 6 & 0 & 0.024728 & 0.089255 & 0.000000 \\ 7 & 1 & 0 & -1.143367 & -1.752192 & 0.000000 \\ 8 & 8 & 0 & 0.105309 & 1.311192 & 0.000000 \\ 9 & 8 & 0 & 1.114990 & -0.728411 & 0.000000 \\ 10 & 6 & 0 & 2.377887 & -0.052641 & 0.000000 \\ 11 & 1 & 0 & 2.481425 & 0.577087 & -0.888655 \\ 12 & 1 & 0 & 2.481425 & 0.577089 & 0.888655 \\ 13 & 1 & 0 & 3.132908 & -0.839915 & 0.000001\end{array}$

Radical species of AN

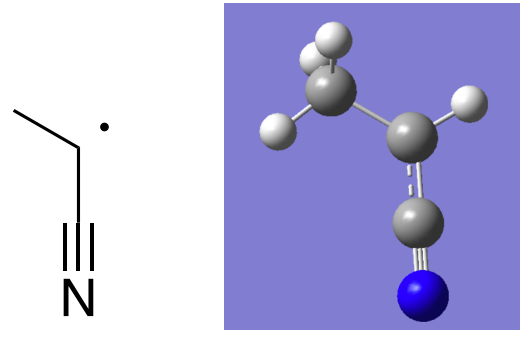

SOMO energy $(\mathrm{eV})=-0.23743$

Standard orientation:

\begin{tabular}{crrrrr} 
Center & Atomic & Atomic & \multicolumn{3}{c}{ Coordinates (Angstroms) } \\
Number & Number & Type & $\mathrm{X}$ & $\mathrm{Y}$ & $\mathrm{Z}$ \\
\hline & & & & & \\
-1 & 6 & 0 & 1.635473 & -0.338666 & 0.000000 \\
2 & 6 & 0 & 0.446694 & 0.570170 & 0.000000 \\
3 & 1 & 0 & 1.342269 & -1.391058 & 0.000012 \\
4 & 1 & 0 & 2.265826 & -0.152886 & -0.880968 \\
5 & 1 & 0 & 2.265840 & -0.152869 & 0.880954 \\
6 & 6 & 0 & -0.862180 & 0.110122 & 0.000000
\end{tabular}




$\begin{array}{rrrrrr}7 & 1 & 0 & 0.598394 & 1.646485 & -0.000001 \\ 8 & 7 & 0 & -1.970322 & -0.285632 & 0.000000\end{array}$

Radical species of EMI

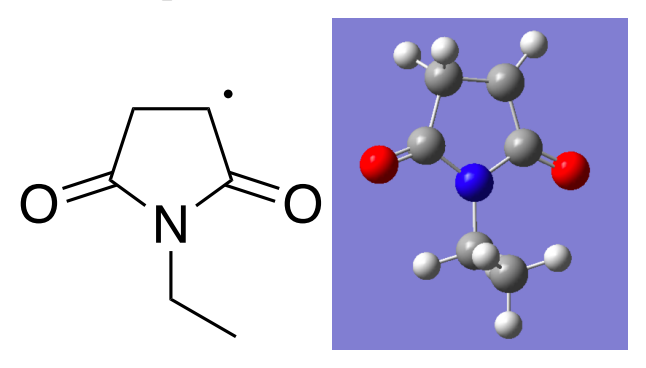

SOMO energy $(\mathrm{eV})=-0.24435$

Standard orientation:

\begin{tabular}{rrrrrr} 
Center & Atomic & Atomic & \multicolumn{2}{c}{ Coordinates (Angstroms) } \\
Number & Number & Type & X & Y & \\
\hline 1 & 7 & 0 & 0.219358 & -0.032660 & -0.251920 \\
2 & 6 & 0 & -0.648516 & -1.101677 & -0.073041 \\
3 & 6 & 0 & -0.402639 & 1.226524 & -0.075479 \\
4 & 6 & 0 & -2.029570 & -0.515953 & 0.254364 \\
5 & 6 & 0 & -1.796067 & 0.952711 & 0.233971 \\
6 & 6 & 0 & 1.636588 & -0.182543 & -0.566637 \\
7 & 8 & 0 & 0.174415 & 2.299767 & -0.180084 \\
8 & 8 & 0 & -0.351240 & -2.275365 & -0.166682 \\
9 & 1 & 0 & -2.374820 & -0.898074 & 1.225776 \\
10 & 1 & 0 & -2.765507 & -0.859146 & -0.486852 \\
11 & 1 & 0 & -2.522755 & 1.733705 & 0.414631 \\
12 & 1 & 0 & 1.738146 & -1.118274 & -1.122296 \\
13 & 1 & 0 & 1.906734 & 0.651850 & -1.219683 \\
14 & 6 & 0 & 2.517775 & -0.193483 & 0.684521 \\
15 & 1 & 0 & 2.411197 & 0.742938 & 1.240826
\end{tabular}




$\begin{array}{llllll}16 & 1 & 0 & 2.251121 & -1.028576 & 1.340190 \\ 17 & 1 & 0 & 3.569556 & -0.304504 & 0.398779\end{array}$

IPBpin

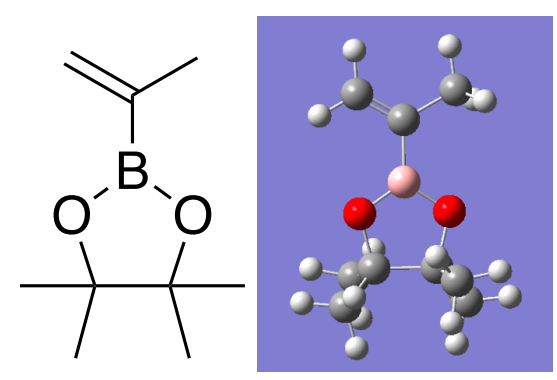

Standard orientation:

\begin{tabular}{rrrrrr} 
Center & Atomic & Atomic & \multicolumn{2}{c}{ Coordinates (Angstroms) } \\
Number & Number & Type & X & Y & Z \\
\hline 1 & & & & & \\
2 & 1 & 0 & 3.302569 & 1.148112 & 0.202536 \\
3 & 1 & 0 & 3.062729 & 1.896152 & -0.564071 \\
4 & 1 & 0 & 4.384894 & 0.976245 & 0.186443 \\
5 & 6 & 0 & 2.525358 & -0.130143 & -0.019910 \\
6 & 5 & 0 & 0.967411 & -0.075341 & -0.018558 \\
7 & 6 & 0 & 3.140763 & -1.306325 & -0.217723 \\
8 & 1 & 0 & 4.226931 & -1.399296 & -0.230806 \\
9 & 1 & 0 & 2.576435 & -2.222061 & -0.375162 \\
10 & 8 & 0 & 0.259332 & 1.075563 & 0.238791 \\
11 & 8 & 0 & 0.155434 & -1.157661 & -0.270212 \\
12 & 6 & 0 & -1.141794 & 0.806338 & -0.047889 \\
13 & 6 & 0 & -1.208410 & -0.768499 & 0.051682 \\
14 & 6 & 0 & -2.150688 & -1.444755 & -0.942655 \\
15 & 6 & -1.410461 & 1.340500 & -1.461558
\end{tabular}




\begin{tabular}{rrrrrr}
16 & 6 & 0 & -1.996754 & 1.561035 & 0.968573 \\
17 & 6 & 0 & -1.488656 & -1.278579 & 1.472156 \\
18 & 1 & 0 & -1.148528 & 2.402597 & -1.494851 \\
19 & 1 & 0 & -0.801122 & 0.819221 & -2.206563 \\
20 & 1 & 0 & -2.464444 & 1.236605 & -1.740252 \\
21 & 1 & 0 & -1.724865 & 1.305021 & 1.995048 \\
22 & 1 & 0 & -1.852292 & 2.638674 & 0.840765 \\
23 & 1 & 0 & -3.061044 & 1.342626 & 0.823481 \\
24 & 1 & 0 & -3.188133 & -1.134864 & -0.771847 \\
25 & 1 & 0 & -1.882395 & -1.212579 & -1.975703 \\
26 & 1 & 0 & -2.097319 & -2.530979 & -0.817092 \\
27 & 1 & 0 & -0.818817 & -0.813128 & 2.202084 \\
28 & 1 & 0 & -2.522747 & -1.084501 & 1.776119 \\
29 & 1 & 0 & -1.318304 & -2.359252 & 1.500273 \\
------------------- & & \\
\hline
\end{tabular}

MMA

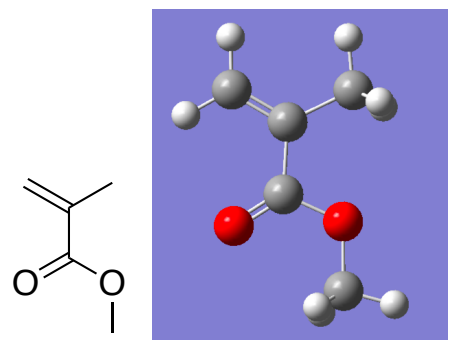

Standard orientation:

\begin{tabular}{|c|c|c|c|c|c|}
\hline \multirow{2}{*}{$\begin{array}{l}\text { Center } \\
\text { Number }\end{array}$} & \multirow{2}{*}{$\begin{array}{l}\text { Atomic } \\
\text { Number }\end{array}$} & \multirow{2}{*}{$\begin{array}{l}\text { Atomic } \\
\text { Type }\end{array}$} & \multicolumn{3}{|c|}{ Coordinates (Angstroms) } \\
\hline & & & $X$ & Y & Z \\
\hline 1 & 6 & 0 & -1.188699 & 0.033656 & 0.000028 \\
\hline 2 & 6 & 0 & -1.508994 & 1.506276 & 0.000138 \\
\hline 3 & 6 & 0 & -2.115516 & -0.932022 & -0.000233 \\
\hline 4 & 6 & 0 & 0.245396 & -0.400170 & 0.000094 \\
\hline
\end{tabular}




$\begin{array}{rrrrrc}5 & 1 & 0 & -1.084771 & 2.005487 & -0.878470 \\ 6 & 1 & 0 & -2.591405 & 1.665500 & 0.000876 \\ 7 & 1 & 0 & -1.083502 & 2.005665 & 0.878013 \\ 8 & 1 & 0 & -3.176770 & -0.699789 & -0.000298 \\ 9 & 1 & 0 & -1.823799 & -1.977132 & -0.000369 \\ 10 & 8 & 0 & 1.084947 & 0.663839 & -0.000083 \\ 11 & 8 & 0 & 0.637391 & -1.550169 & 0.000250 \\ 12 & 6 & 0 & 2.482940 & 0.338916 & -0.000137 \\ 13 & 1 & 0 & 2.742427 & -0.241619 & 0.889312 \\ 14 & 1 & 0 & 2.742042 & -0.243062 & -0.888746 \\ 15 & 1 & 0 & 3.006307 & 1.295659 & -0.000999\end{array}$

\section{References}

[1] Mayo, F. R.; Lewis, F. M. J. Am. Chem. Soc. 1944, 66, 1594-1601.

[2] (a)Van Herk, A. M.; Dröge, T. Macromol. Theory Simul. 1997, 6, 1263-1276.; (b)van de Wouw, H. L.; Awuyah, E. C.; Baris, J. I.; Klausen, R. S. Macromolecules 2018, 51, 6359-6368.

[3] Gaussian 16, Revision A.03, M. J. Frisch, G. W. Trucks, H. B. Schlegel, G. E. Scuseria, M. A. Robb, J. R. Cheeseman, G. Scalmani, V. Barone, G. A. Petersson, H. Nakatsuji, X. Li, M. Caricato, A. V. Marenich, J. Bloino, B. G. Janesko, R. Gomperts, B. Mennucci, H. P. Hratchian, J. V. Ortiz, A. F. Izmaylov, J. L. Sonnenberg, D. Williams-Young, F. Ding, F. Lipparini, F. Egidi, J. Goings, B. Peng, A. Petrone, T. Henderson, D. Ranasinghe, V. G. Zakrzewski, J. Gao, N. Rega, G. Zheng, W. Liang, M. Hada, M. Ehara, K. Toyota, R. Fukuda, J. Hasegawa, M. Ishida, T. Nakajima, Y. Honda, O. Kitao, H. Nakai, T. Vreven, K. Throssell, J. A. Montgomery, Jr., J. E. Peralta, F. Ogliaro, M. J. Bearpark, J. J. Heyd, E. N. Brothers, K. N. Kudin, V. N. Staroverov, T. A. Keith, R. Kobayashi, J. Normand, K. Raghavachari, A. P. Rendell, J. C. Burant, S. S. Iyengar, J. Tomasi, M. Cossi, J. M. Millam, M. Klene, C. Adamo, R. Cammi, J. W. Ochterski, R. L. Martin, K. Morokuma, O. Farkas, J. B. Foresman, and D. J. Fox, Gaussian, Inc., Wallingford 
CT, 2016 